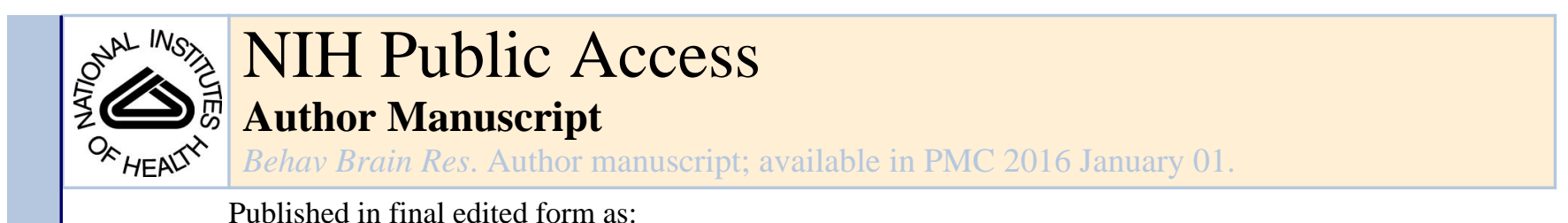

Published in final edited form as:

Behav Brain Res. 2015 January 1; 0: 32-44. doi:10.1016/j.bbr.2014.03.039.

\title{
PERIPARTUM DEPRESSION AND ANXIETY AS AN INTEGRATIVE CROSS DOMAIN TARGET FOR PSYCHIATRIC PREVENTATIVE MEASURES
}

\author{
Jessica A. Babb ${ }^{a}$, Kristina M. Deligiannidis ${ }^{b}$, Christopher A. Murgatroyd ${ }^{c}$, and Benjamin C. \\ Nephew ${ }^{a}$ \\ Jessica A. Babb: jessica.babb@tufts.edu; Kristina M. Deligiannidis: kristina.deligiannidis@umassmemorial.org; \\ Christopher A. Murgatroyd: c.murgatroyd@mmu.ac.uk; Benjamin C. Nephew: bcnephew@aol.com \\ aDepartment of Biomedical Sciences, Tufts University Cummings School of Veterinary Medicine, \\ North Grafton, MA 01536, USA \\ bDepartments of Psychiatry and Obstetrics \& Gynecology, University of Massachusetts Medical \\ School, Worcester, MA 01605, USA \\ 'School of Healthcare Science, Manchester Metropolitan University, Manchester, UK
}

\begin{abstract}
Exposure to high levels of early life stress has been identified as a potent risk factor for neurodevelopmental delays in infants, behavioral problems and autism in children, but also for several psychiatric illnesses in adulthood, such as depression, anxiety, autism, and posttraumatic stress disorder. Despite having robust adverse effects on both mother and infant, the pathophysiology of peripartum depression and anxiety are poorly understood. The objective of this review is to highlight the advantages of using an integrated approach addressing several behavioral domains in both animal and clinical studies of peripartum depression and anxiety. It is postulated that a greater focus on integrated cross domain studies will lead to advances in treatments and preventative measures for several disorders associated with peripartum depression and anxiety.
\end{abstract}

\section{Keywords \\ peripartum depression; depression; anxiety; stress; PTSD; autism}

\section{INTRODUCTION}

Women commonly experience depressive and anxiety disorders during reproductive years [1]. Annually, nearly one-half million infants are born to mothers with depression [2].

(C) 2014 Elsevier B.V. All rights reserved.

Correspondence to: Benjamin C. Nephew, bcnephew@aol.com.

Publisher's Disclaimer: This is a PDF file of an unedited manuscript that has been accepted for publication. As a service to our customers we are providing this early version of the manuscript. The manuscript will undergo copyediting, typesetting, and review of the resulting proof before it is published in its final citable form. Please note that during the production process errors may be discovered which could affect the content, and all legal disclaimers that apply to the journal pertain. 
Approximately $18.4 \%$ of women suffer from antepartum depression, and approximately $19.2 \%$ of mothers develop a depressive disorder within several weeks of delivery [3]. Depression during pregnancy is a major risk factor for postpartum depression [4]. Peripartum depression (PPD), occurring during pregnancy or within a short time after delivery, is a risk factor for maternal suicide which accounts for up to $20 \%$ of postpartum deaths in depressed women [5]. Peripartum anxiety disorders are also common, with a prevalence rate of $21.7 \%$ during the $3^{\text {rd }}$ trimester of pregnancy, and $11.1 \%$ during the first 3 postpartum months [6,7]. PPD and anxiety are associated with a diverse array of adverse effects on offspring, spanning from birth to adulthood, and are often comorbid [8]. A growing literature supports the hypothesis that PPD and anxiety are risk factors for the later development of psychiatric disorders in offspring. The temporal specificity of PPD and anxiety, combined with how these highly comorbid disorders may lead to transmission of psychiatric phenotypes in offspring make this topic ideal for cross domain research [9]. Although PPD is associated with several disorders and the preventative potential of focusing on this area for enhancing the health of offspring and future generations is great, there are few animal models devoted to this topic. Whilst clinical phenotyping of PPD and anxiety has improved, most animal models still focus on a relatively small subset of symptoms. And compared to the available animal literature on depression and anxiety in males, there is staggeringly little attention paid to female-specific symptomology, with even less attention paid to the maternal transition itself.

The overlapping symptomatology domains of PPD and anxiety are not novel; however, the idea that treatments could be improved by targeting several symptoms has received greater attention recently. Deficiencies in maternal care may not necessarily be ameliorated by classic antidepressant treatments such as SSRI's which can be effective at decreasing general anhedonia. This therefore indicates a need for the assessment of both depression symptoms and maternal care [9-13], especially since many of the adverse effects of PPD and anxiety on offspring are mediated through maternal care [14]. Aggression and hostility are also concerns with respect to how PPD and anxiety affect family dynamics (increasing family conflict and adverse parental behaviors) even when there is little risk of physical aggression towards offspring [15-18]. Therefore, considering the behavioral 'phenotype' of the entire family may be an effective treatment option [18]. Two other behavioral domains that should be considered in both research and treatment of PPD and anxiety are restlessness/agitation and impaired concentration and decision making, which are more prevalent in PPD than non-maternal depression [19]. Another important phenotypic factor that mediates many of the socio-economic and cultural differences in rates of maternal mood disorders is social environment and behavior. In general, women with low levels of social support are at an increased risk for PPD and anxiety and increased social support has beneficial effects in depressed mothers [20-25].

The use of a cross domain approach with PPD and anxiety should aid in the understanding of specific physiological endophenotypes involved in these disorders. For example, although oxytocin (OXT) is known to be involved in anxiety, social affiliation, and the physiological processes of parturition and lactation, research on PPD is just starting to focus on the OXT system despite the observations that depressed mothers are likely to be anxious and have difficulties with infant bonding as well as impaired lactation. Depressed and anxious 
mothers often have difficulties nursing and are more likely to stop nursing earlier [26, 27], a behavior highly dependent on the OXT system. Premenstrual dysphoric disorder (PMDD) and a past history of depressive symptoms during past oral contraceptive use are two other risk factors for PPD, suggesting that the general domain of non-maternal reproductive endocrinology difficulties should be considered in research and treatment of PPD and anxiety [28-31]. Depression and anxiety in women undergoing assisted reproductive techniques may have a significant endocrine component and not simply be a result of the stress associated with the process [32,33]. Furthermore, social deficits in both the mother and infant could also be associated with the OXT system. Therefore, although not commonly represented in animal models, dysregulation of the OXT system is a potential endophenotype of PPD and anxiety, and translational neuroscience could benefit from the inclusion of this system in study designs.

In this review, a novel animal model of PPD and anxiety and the advantages of the crossdomain research approach using this model are discussed. The authors propose that modeling phenotypic clusters (i.e. cross domain) clinically observed within peripartum maternal depression and anxiety and infant/child neurodevelopment can be useful for translational neuroscience. We begin by describing how such phenotypic clusters (or behavioral domains) are assessed (section 1.1.), then describe the potential advantages of using an animal model in a cross domain approach to study the negative consequences of PPD and anxiety on both mother and offspring (section 2). The subsequent sections then review how PPD and anxiety may increase the risk of depression and anxiety (section 3), autism spectrum disorders (section 4), and posttraumatic stress disorder (section 5) in the offspring of depressed and anxious mothers through discussion of the multiple domains affected by PPD and anxiety and the few cross domain studies on these topics. We then summarize and discuss these topics, and provide some conclusions and suggestions for future directions of the field.

\subsection{Assessing phenotypic clusters within peripartum maternal depression and anxiety and infant/child neurodevelopment}

Many domains of behavior which have been modeled in animals have been examined in humans, some studied in depression/anxious peripartum women and others focused on their exposed infants/children. Since a main limitation of human studies is the inability to directly examine neurochemistry and neurocircuitry in human pregnant mothers and infants, research has focused on physiology, development and self-reported or observed symptomatology. Clinical research is moving towards the increased study of phenotypic clusters [34] and away from the study of 'pure' diagnoses since many psychiatric syndromes represent a spectrum of illness inclusive of abnormalities in several overlapping domains of behavior and physiology. The best examined domains/systems in depressed/anxious peripartum women include negative valence, cognitive systems and perception of self/others while those best studied in depression/anxiety exposed infants/children involve studies of fear, anxiety, attention, attachment formation, cognition and perception of self/others. Few clinical studies have examined positive valence systems and arousal/modulatory systems (i.e. circadian rhythms). Clinical research studies are lacking in understanding the underlying pathophysiology of peripartum depressive/anxiety disorders and how 
psychopathology is transmitted to the offspring. Likewise, the adverse neurodevelopmental effects on infants and children as measured by clinical testing are well examined, but the underlying causes and the longitudinal course of these deficits across childhood into adulthood are poorly understood. One approach is to develop animal models of peripartum depression/anxiety based on an aggregate of behavioral domains common to anxiety/ depression e.g. negative or positive valence systems. In the offspring one can then study domains shown to be affected by human peripartum depression/anxiety which are observable in animal models e.g. fear, anxiety, attention. Using an aggregate of domains which cluster in both depressive and anxiety disorders allows the study (i.e. at the genetic, molecular, cellular, circuit, physiology and behavior levels) of pathophysiology along a continuum. Understanding the underpinnings of clusters of behavioral domains allows investigators to then compare and contrast similarities and differences to psychiatric illnesses characterized by shared or differing clusters. While certain types of analysis will be easier studied in humans than non-human animals and vice versa, translational neuroscience will be instrumental to provide evidence for the validity of target genes identified in human studies using peripheral blood samples [35], examine transmission of psychopathology risk at the molecular and cellular levels and to examine neurocircuitry for each phenotypic cluster, across species [36].

\section{TOWARDS AN INTEGRATIVE CROSS-DOMAIN ANIMAL MODEL OF PPD AND ANXIETY}

It has been postulated that animal models that include multiple domains of neuropsychiatric models and the appropriate etiological and interactive context will have greater construct validity and clinical relevance [37]. Current animal models for many disorders often fail to include multiple associated symptom domains. The lack of efficacy with modern treatments for depression may be due to the incorrect assumption that abstract behavioral tests such as forced swim, tail-suspension, and saccharin preference are appropriate analogues for human depression [38]. These tests have produced treatments which do not work much better than placebo for mild and moderate depression $[39,40]$ and need to be replaced with more ethological paradigms. A further complication with the translation of much of the animal research on depression and anxiety to PPD and anxiety patients is that most animal studies are restricted to male subjects and there are significant sex differences in depression [41]. While it is acknowledged that gene $\mathrm{x}$ environment interactions are a significant feature in the etiology of depression and anxiety, the environmental components of animal studies often lack ethological relevance due to an emphasis on standardization and experimental control. Efforts to enhance the experimental control in studies of the role of stress in depression have decreased ethological relevance and key cross domain etiology and interactions. For example, environmental exposure to stress, a key predictor of depression and anxiety, is frequently modeled through the use of chronic restraint, doses of exogenous corticosterone, and exposure to a randomized variety of robust stressors in chronic "mild" stress paradigms. These types of stressors have substantial physiological components that may confound behavioral results and do not mimic important clinical factors, such as social stress. Requiring greater cross domain relevance in animal models will increase the ethological relevance of animal models and increase the translational effectiveness of novel 
treatments and preventative measures. While this is a difficult task in many animal models and research settings, the study of maternal mood disorders is well-suited to an integrated cross domain ethological approach.

One model of PPD and anxiety using the cross domain approach is the chronic social stress (CSS) model, which consists of one hour daily exposures of a lactating female to novel males for two weeks during lactation $[42,43]$. This challenge affects the maternal behavior of the stressed dams and also represents an early life stress for the F1 and F2 offspring of these dams [44-46]. The specific use of social stress in stress induced depression and disease models consistently produces data and conclusions which are particularly clinically relevant [47]. It is argued that the use of social stress in the CSS model is essential to the effective development of an integrative phenotypic model, since the use other stressors that generate changes in affective behaviors could have limited construct validity that may limit their ultimate translational value and clinical relevance, even if a cross domain approach is used. For example, hours of daily restraint stress may decrease maternal care and increase anxiety primarily through a physiological mechanism that is not common in the majority of clinical settings. Another example would be decreased maternal care following exposure to chronic mild stress paradigm that uses sudden changes in light cycle. A change in maternal care in this type of paradigm could be due to a sudden change in light cycle and not the chronic array of stressors. A key goal for improving animal models of psychiatric disorders is to use ethologically relevant methods to generate clinically relevant changes in both behavioral and physiological domains.

In addition to the use of social stress, two other novel aspects of the CSS model are the focus on maternal care to measure changes in anhedonia and the inclusion of lactation measures. Maternal care is an extremely rewarding behavior for rat dams, who will choose access to their pups over cocaine when sensitized to cocaine [48], and human mothers, who are more likely to stay in recovery from addiction when kept together with their children [49-51]. While most models of PPD and anxiety use standard tests such as forced swim or saccharin preference to assess depression associated anhedonia in rodents, maternal care is both a more ethologically relevant assessment as well as a clinically important treatment target. Some of the greatest concerns about PPD and anxiety are their adverse effects on offspring, and these effects are mediated through deficiencies in maternal care [14]. In this way, the use of maternal care in the CSS model represents the cross domain approach concept, as the domains of anhedonia and offspring care are simultaneously assessed. In a similar fashion, a major challenge with PPD associated anxiety for both clinicians and mothers is with the adverse effects of anxiety on maternal care [52,53]. The CSS paradigm attempts to model this relationship by using the expression of non-maternal care behaviors expressed during maternal care tests (excessive nesting, self-grooming, locomotor activity) as an integrated measure of restlessness and anxiety [46]. Instead of standard tests of anxiety such as the elevated plus maze, open field, and the light/dark box, where dams are tested away from their pups in a novel environment, the assessment of non-maternal behaviors during maternal care testing may be a more translationally useful measure of maternal-specific anxiety and restlessness. In addition to the benefits of using maternal care to assess anhedonia and anxiety, the CSS model includes several other behavioral and physiological domains of PPD and anxiety. These include increased aggression in animals actively 
exposed to chronic social stress [42], impaired decision making, and impaired lactation. These behavioral effects are associated with neuroendocrine changes which suggest that CSS has etiological and mechanistic similarities with clinical PPD and anxiety, including disruptions to the hypothalamic-pituitary-adrenal (HPA) and hypothalamic-pituitary-gonadal (HPG) axes [44-46]. CSS decreases maternal care both during active exposure to the social stressor during lactation and has more robust effects as an early life stress [44, 46], paralleling the transgenerational effects of these disorders [54-56]. Study of the offspring of early life CSS exposed dams reveals decreased social behavior in both male and female offspring [44], similar to the children of depressed mothers who have an increased risk for several disorders which involve deficits in social behavior [14, 56-59]. It is suggested that PPD and anxiety are ideal targets for the development of preventative measures for a variety of psychiatric illnesses including depression, anxiety, autism, and PTSD, due to its substantial developmental importance and associated transgenerational effects.

\section{PPD AND ANXIETY AS A RISK FACTOR FOR DEPRESSION AND ANXIETY IN OFFSPRING}

The next section will briefly review the evidence for neurodevelopmental effects (i.e. motor, adaptive, personal-social, language and cognitive) and psychiatric disorders associated with maternal antepartum (1) and postpartum (2) depression and anxiety, and discuss evidence of proposed cross domain mechanisms by which maternal depression and anxiety/stress is transduced from mother to fetus/infant that comes from clinical (3) and animal studies (4).

\subsection{Obstetrical and neurodevelopmental effects associated with maternal antepartum depression and anxiety}

Untreated depression and anxiety during pregnancy pose risks to the health of the pregnancy and infant development. Several obstetrical and neonatal complications have been implicated as adversely affecting brain development [for a meta-analysis review see 37 (Alder et al, 2007)]. Antepartum anxiety/stress is associated with preterm birth [60, 61] and low birth weight $[61,62]$, while antepartum depression is associated with inadequate maternal weight gain [63] and with increased risks of: preeclampsia [64], paradoxically with both preterm birth [62, 65-67] and prolonged pregnancy [68], caesarian delivery [69], delivery of a low birth weight infant [66], fetal distress [70] and neonatal care unit admission [69]. The risk of poor birth outcomes such as having a low birth weight or small for gestational age infant or delivering preterm rises 5-7\% for each point increase in antepartum depression score as measured by the Beck Depression Inventory [71].

PPD affects the developing fetal autonomic and central nervous systems. Antepartum maternal stress, depression, and anxiety have been associated with changes in fetal (in utero) heart rate, sleep pattern and movements $[72,73]$ and alterations in maternal and placental stress-related hormones, associate with increased infant fearful temperament [74-76]. In neonates, lower scores for the Brazelton Neonatal Assessment Scale, on neurological evaluation and cardiac vagal tone are associated with exposure to antepartum maternal anxiety/stress [72]. In infants, antepartum depressionis associated with infant growth 
stunting at age 6-8 months [77] and poorer scores on the Bayley Scales of Infant Development at 8 and 24 months age [78, 79].

Antepartum psychosocial stress and maternal cortisol may program infant stress regulation by altering stress reactivity. Antepartum stress is associated with elevated maternal adrenocorticotropic hormone (ACTH) and cortisol at 28 weeks gestation [80] and elevated cortisol in third trimester women with anxiety comorbid with depression [81]. Exposure to elevated maternal cortisol during late gestation is associated with exaggerated infant cortisol response to a physical stressor and antepartum maternal stress predicts a slower rate of behavioral recovery [82]. Higher maternal antepartum cortisol levels are associated with poorer infant cognitive performance [83]. Antepartum maternal stress is also associated with increased behavioral reactivity in the offspring [84]. Similarly, peripartum maternal depression, as opposed to pre-pregnancy history of the disorder, is associated with higher infant cortisol reactivity at 6 months of age [85]. Neonates of antepartum depressed mothers have higher cortisol levels and lower dopamine and serotonin levels, less optimal orientation, motor, autonomic stability, abnormalities in laterality of frontal EEG [86] and lower vagal tone compared to neonates born to non-depressed mothers [87]. Infants of antepartum depressed mothers also spend more time fussing/crying, spend less time awake/ alert and show more signs of stress behavior than neonates of postpartum depressed or nondepressed mothers [86]. Neurophysiological differences in antepartum depression exposed neonates may reflect not only abnormalities of early brain processing but may predict later emotional processing or stress vulnerability, with abnormally asymmetric frontal EEG patterns representing a marker of differences in stress response [88] and lower vagal tone as an indicator of stress vulnerability [89].

Antepartum depression is associated with infant disorganized attachment at 1 year of age [90] and with adverse cognitive development, while high levels of maternal antepartum anxiety is associated with poor social-emotional development at 18 months of age [91]. Depressive symptoms are associated with lower scores on scales of cognitive development and fine motor development [91]. Not surprisingly, antepartum depression may affect male and female fetuses differently. Newborns exposed to antepartum depression attain lower scores on motor skills than unexposed newborns, with male newborns performing worse than females. At 1 year of age, male infants exhibited higher generalized anxiety scores than control male infants; both male and female total anxiety scores were higher in the infants exposed to antepartum depression compared to unexposed infants. Female infants exposed to antepartum depression showed more externalizing behaviors including oppositional/ defiant aggression behaviors than controls, but both sexes exposed to antepartum depression had a higher frequency of these behaviors compared to unexposed infants [92].

Antepartum anxiety may increase the risk of childhood developmental and psychiatric disorders by adversely affecting infant emotional development [93]. Antepartum maternal anxiety is associated with increased child internalizing difficulties age at 7-8 years of age while antepartum maternal depression is associated with externalizing difficulties and a small decrease in verbal IQ [94]. In children, antepartum anxiety is associated with a greater incidence of mixed handedness [95], which has been associated with a range of neurodevelopmental problems including dyslexia, ASD and ADHD, possibly indicating that 
exposure to antepartum anxiety affects another index of neurobehavioral organization, brain laterality [95]. Exposure to antepartum maternal anxiety/stress is associated with poorer attention, hyperactivity, behavioral and emotional problems in children aged 8-9 years [96] and impulsivity during performance of cognitive tasks in 14 and 15 year olds [97]. Across gestation, high levels of pregnancy-specific anxiety are associated with lower visuospatial working memory performance in boys and girls at 6-9 years age [98] and in girls, inhibitory control was impaired. In brain imaging studies, anxiety at 19 weeks gestation is associated with region-specific gray matter volume reductions in the prefrontal cortex, premotor cortex, medial temporal lobe, lateral temporal cortex, postcentral gyrus and the cerebellum [99].

\subsection{Neurodevelopmental effects associated with maternal postpartum depression and anxiety}

Postpartum depression has been associated with a broad negative impact upon infant and child emotional and functional development, including difficult infant and childhood temperament [100, 101], attachment insecurity [102], developmental [103] and cognitive delays [104], behavioral problems [102], and difficulties with social interaction [105]. Maternal depression across the first postpartum year is associated with poor infant social engagement, fear regulation, and high stress reactivity [101]. The strongest effects of postpartum depression appear to be on early childhood cognitive development, including language and intelligence, and on child behavior up to five years postpartum. Children of mothers with postpartum depression performed significantly less well on cognitive tasks at 18 months, especially boys compared to girls and unexposed children [106]. In studies which have found cognitive delay in boys born to depressed mothers, low birth weight infants are at increased risk. Infants of postpartum depressed mothers have lower cognitive scores over the examination period (6-18 months of age), with girls increasing their cognitive score as compared to boys, pointing to the importance of looking at the contribution of biological sex [107]. Postpartum depression may be associated with poorer performance on perceptual, motor and verbal tasks in boys compared to girls or children born to non-depressed mothers [108], but not all studies agree [109].

The impact of maternal depression has effects beyond infancy, as one-third of school-aged children (ages 5-17 years of age) of depressed mothers suffer from depressive, anxiety or disruptive disorders [110]. Some studies of child behavior show correlations between postpartum depression and increased child neurotic and antisocial behavior [111] at 5 years of age, yet others do not [112]. Postpartum maternal anxiety, similar to antepartum anxiety, is associated with increased internalizing problems while postpartum depression is associated with increases in internalizing and externalizing problems and a small decrease in verbal IQ [94]. No sex differences were noted in this very large (i.e. 3,298 mother-offspring pairs) sample. Children of postpartum depressed mothers are more likely than controls to experience depression themselves by 16 years age and may be partially explained by insecure attachment, low early childhood ego-resilience and by exposure to family adversity [113]. In a moderate-sized longitudinal study, maternal antepartum depressive symptoms were associated with externalizing problems in children of both sexes and postpartum depressive symptoms were associated with lower psychosocial functioning and externalizing problems in boys only [114]. In a meta-analysis of 193 studies, maternal depression was 
significantly related to higher levels of internalizing, externalizing and general psychopathology and negative affect/behavior and to lower levels of positive affect/behavior [115]. All associations were small in magnitude, highlighting the importance of understanding and measuring potential moderators that enhance risk, including timing of the exposure (i.e. antepartum, postpartum), the sex of the child, sociodemographic variables, etc.. Some studies suggest that exposure to maternal depression during the first year of life, rather than a history of the disorder or antepartum depression, predicts internalizing and total behavior problems [116], others suggest that chronic maternal depression has longer-lasting effects on child development [117]. Since a significant proportion of women with postpartum depression go on to develop chronic depression [118], the exposure may in many cases be prolonged, affecting several critical periods sensitive to the effects of postpartum or chronic depression. However, there is debate whether negative effects of postpartum depression are lasting, and some studies find no association between antepartum or postpartum depression exposure and neurodevelopmental outcomes [119].

\subsection{Transmission of stress-evoked psychopathology risk: Clinical studies}

The mechanism through which maternal psychological stress and PPD is transduced from the pregnant or postpartum mother to the fetus/infant is unclear, but is likely multidimensional. Contributing influences may include interactions between the maternal environment in utero, placental changes, epigenetic programming and postpartum exposures. In alignment with the fetal origins hypothesis of adaptation and disease, programming of physiological systems by the antepartum environment prepares the fetus for the postpartum environment. Non-genomic modifications of the phenotype through developmental plasticity can offer adaptive value as it aims to match an individual's responses to the environment predicted to be experienced. If the responses are mismatched, then the risk of disease increases. When mismatches in environments occur, altered stress activity or reactivity may become maladaptive in sex-specific ways $[36,120]$ and may be transmitted to more than the immediately succeeding generation [121].

Antepartum exposure to maternal PPD, anxiety, or stress during sensitive periods of human neurodevelopment may contribute to enduring effects on psychological health either through the fetus' direct physiological adaptation to the intrauterine environment or an interaction of those effects with inherited genetic risk. The exposure often transverses the antepartum/ postpartum period, so long-term behavioral outcomes are impacted by both environments. Dysregulation of the maternal HPA axis, as associated with depression and anxiety, may impact fetal development by altering placental function. Increased serum cortisol and catecholamine levels may alter uterine blood flow or induce uterine irritability [122] and these alterations could initiate early parturition or preterm birth. Additionally, altered gene regulation within the placenta has functional consequences for both fetal and infant development and is associated with adverse birth outcomes. For example, antepartum maternal anxiety is negatively correlated with placental $11 \beta$-hydroxysteroid dehydrogenase- 2 mRNA levels, thus may influence the exposure of the fetus to circulating maternal stress hormones $[123,124]$. The sexually dimorphic placental sensitivity to stress could represent one mechanism for fetal programming in a sex-specific manner [125]. 
Antepartum anxiety/stress and depression are associated with HPA axis and epigenetic changes in the offspring, a growing literature which has similarities to that which has been reported in animal studies [126-128]. Epigenetic modifications may be a mechanistic link between maternal adversity and infant and child outcomes [35, 129]. Work in animal models, and a more limited but growing literature in human studies, demonstrates that epigenetic changes occur in response to environmental stress, some in a sex-specific manner [130]. Evidence of epigenetic modification within HPA pathways [131, 132], including the glucocorticoid receptor [133] and the serotonin transporter [134] have been identified in human offspring. Antepartum stress, for example, could cause alterations in fetal stress reactivity $[101,135]$ and the ability to terminate a stress response through epigenetic mechanisms, however it is not known how fetal exposure to stress hormones directly affects brain development [136]. The type, duration and timing of the exposure (e.g. periconceptional, late gestation vs. postpartum) and underlying genetic and environmental risk factors may be important to the later manifestation of sex differences in neurodevelopment and/or psychopathology.

Postpartum depression effects may be mediated by maternal behaviors including dysfunctional attachment, maternal coping and caregiving behavior, thus indirectly increasing the risk for delayed cognitive development and child behavior problems. Negative parenting behaviors of depressed mothers range from withdrawal to rejecting, less sensitive [101] and harsh parenting [137, 138] while those reported of anxious mothers are of being negative and intrusive [101, 139, 140]. Postpartum effects may be moderated in part by epigenetic modifications: deprivation of parental care is associated with significant epigenetic changes in genes implicated in brain development [141].

\subsection{Transmission of stress-evoked psychopathology risk: Animal studies}

Some approaches to research of the mother infant bond cannot be employed in humans due to their ethical implications and to potential harm they pose for mother and child health. Thus, translational approaches are a crucial way to dissect this relationship through bridging gaps between basic animal research and medical practice. Translational research approaches, with its introduction in the NIH Roadmap initiative [142, 143], have been important in the field of psychiatry, and especially to affective disorders, including depression and anxietyrelated disorders. Most efforts have been devoted to the "bench to the bedside" (from animals to humans, or from basic to clinical research) approaches focusing on the design of animal models (particularly using rodents) that would be relevant to study the human disorders and to predict the therapeutic outcomes. Unfortunately, less research follows the opposite direction, using the reverse-translational approach and thus going from the bedside to the bench (from humans to animals) [144, 145]. However, when trying to assess the function of mechanisms discovered in animal models in the pathophysiology of human disorders and developing new treatments for these conditions, such reverse-translational approaches are crucial. For example, the role of hippocampal neurogenesis in the pathophysiology of depression and in the therapeutic efficacy of pharmacological treatments has been shown using rodent models [146-148], and then confirmed in human studies [149, 150]. Research on knockouts and polymorphisms, in animals and humans respectively, at the level of the gene for brain-derived neurotrophic factor (BDNF) represents a powerful 
tool for understanding the involvement of this neurotrophin in the pathogenesis of anxiety disorders [151].

Such translational approaches obviously require rodent models that are suitable to study the clinical condition. Maternal behavior investigations in animals have proven valuable to understand the mother-infant relationship. Maternal behavior in rodents is well-described in brief, it is composed of four major features: retrieval behavior, nest building, nursing behavior, and pup grooming. Because these behavioral patterns are well characterized, rodent maternal behavior can be quantified in response to various contexts or treatments. Numerous studies in rodents and humans demonstrate that the quality of maternal care, and early postnatal and prenatal experiences can have long term effects in adulthood on stress reactivity and behavior [152]. Mice stressed during early postnatal life show increased anxiety-related behaviors, and altered HPA regulation [153]. Rats stressed during prenatal life show similar behavioral and endocrine programming [154]. Several animal studies have demonstrated the important modifiable reflects of early maternal behaviors [45, 155-158]. Notably, changes in maternal care, through CSS, lead to altered neuropeptide regulation in the PVN and SON [45]. Meaney and colleague's studies have linked increased arch back nursing, and licking and grooming to enhanced HPA axis feedback regulation and reduced anxiety-related behavior through increased glucocorticoid receptor (GR) expression in the hippocampus [159]. Translating to the animal literature, clinical studies, as reviewed above, find that indices of prenatal stress such as maternal antepartum depression or anxiety also predict altered HPA reactivity [160], negative emotionality in infants [161], conduct disorders, and emotional problems in children $[154,162]$. However, very few studies have identified candidates for maternal behaviors in humans that may be the equivalent of rat licking and grooming. Strikingly, in rats the effects of the licking and grooming can be mimicked by stroking the pups with a brush [154]. Sharp and colleagues recently reported the first investigation in humans of moderation of prenatal stress effects by early human tactile stimulation on behavioral and physiological stress reactivity in infancy [163]. Specifically, they found that the effect of maternal antepartum depression on infant reactivity was modified by tactile stimulation over the first weeks of life, assessed by how often mothers reported stroking their babies.

Skeptics may suggest that animal models have limited translational relevance to largely human specific features, such as maternal behaviors. For instance, in relation to other mammals, humans have vastly greater and more complex social competences [164]. Variations in well-established dimensions of parenting, such as sensitivity, intrusiveness, or hostility with effects on attachment security, emotionality and social attributions may be expected to be the most salient for long term effects [165]. Equally, however, long term parental effects on multiple physiological systems, are common in biology, and likely to be mediated via epigenetic modifications $[153,166]$. These may represent an evolved capability for environmentally sensitive plasticity over a limited number of generations, which could be particularly important in species, such as humans, with lengthy time periods between generations and hence only slow genotypic selection in relation to changing environmental conditions [154]. Importantly, tactile stimulation derived from parental care has immediate effects on endocrine systems that regulate somatic growth in rodents [167], and humans [168] suggesting that the ability of the infant to respond to specific forms of 
parental care is conserved at least among mammals. The genetic mechanisms in glucocorticoid regulation are highly conserved across species $[169,170]$, and so an effect of tactile stimulation on GR expression may have been conserved across rodents and humans. The examination of dynamic gene expression and epigenetic mechanisms in infants is currently limited to peripheral tissue, however against the background of extensive animal work demonstrating differences in GR expression and epigenetic regulation, it would be important to investigate links between peripheral and CNS gene regulation. Importantly, it also needs to be tested whether stroking through skin-to-skin contact is the direct mechanism or only a proxy for another causal aspect of parenting. To address these questions it would appear imperative to further back-translate findings from human studies to animal models. Such translational cross-talk between basic research experiments and the clinic would be important to allow fine-tuning of animal models to address such pertinent questions.

\section{PPD AND ANXIETY AS A RISK FACTOR FOR AUSTISM SPECTRUM DISORDERS IN OFFSPRING}

There are several lines of evidence indicating that PPD and anxiety may be a relevant focus area for cross domain studies of autism spectrum disorders (ASD). Given the diversity in ASD phenotypes and the estimate that the environmental component of autism is $60 \%$ [171], it is clear that these disorders involve substantial gene by environment interaction. A recent study has reported a significantly increased prevalence of ASD in the offspring of mothers exposed to high levels of child abuse [172], and the relative risk of ASD has been reported to be twice as high in children of mothers who are diagnosed with a psychiatric illness [173]. Schizophrenia, depression, and personality disorders are all more common in the mothers of autistic children [174]. Parental psychiatric history could represent both a genetic and environmental risk [175]. Family members of ASD patients have elevated levels of major depression and social phobia that are not explained by the stress of raising an autistic child since the majority of depression cases develop prior to the birth of an affected baby [176, 177]. In animal studies, a genetic link between the lateral septum and medial preoptic area of the maternal brain and pathways involved in ASD in rodents has been proposed [178, 179].

Both PPD and ASD involve disruptions in OXT physiology and function. OXT has been known to be involved in the control of mammalian social behavior for decades, yet it has only recently been targeted as a treatment for human disorders which involve disrupted social behaviors. OXT mediates social bonding, anxiety, aggression, and trust in several mammals, including humans [180, 181], and decreased OXT during pregnancy is associated with an increased risk for postpartum depression [182]. Several studies have documented OXT mediated effects of early social environment on social behavior in rodents [183-186], and it was concluded that OXT may play a key role in the development of social behavior. Elevated basal plasma OXT is associated with distressed pair bonds [187], and increased OXT in females correlates with elevated attachment anxiety [188]. Depressed women are also more likely to display greater variability in peripheral OXT release in response to a stressful situation [189], and higher OXT is associated with elevated anxiety in children with high functioning autism as well as healthy controls [190]. Genetic variants in the OXT gene (single nucleotide polymorphisms) [191] and altered OXT receptor gene promoter 
methylation [192] have been implicated in ASD. Intranasal OXT administration improves repetitive and social deficits in autistic patients, and is currently being used in clinical trials for the treatment of ASD [193]. Induced or augmented births and obstetric complications $[194,195]$ increase the risk of autism in the offspring, which may involve an OXT mediated mechanism [196], as a single neonatal OXT treatment (mimicking oxytocin-induced human labor) has long term effects on neural dopaminergic and serotonergic systems in rodents [197]. Furthermore, early weaning and suboptimal breastfeeding practices are associated with increased risk for ASD [198-200] in offspring, and it is postulated that this association may involve an insulin growth factor (IGF) deficiency in the newborn [201]. The robust associations between ASD, OXT and nursing suggest that the early life stress protocols are ideal models for cross domain studies of the role of lactation in ASD, as lactation is commonly disrupted in women suffering from postpartum depression and/or anxiety [202206]. It is postulated that treatments directed at ensuring maternal health may serve as preventative measures for depression, anxiety, and ASD in the offspring of stressed mothers and future generations.

The introduction of PPD in a discussion of ASD research also introduces the potential role of parental care due to evidence that the adverse psychological effects of postpartum depression and anxiety are mediated through deficits in maternal care [14]. When the associations between psychiatric illness and maternal depression are combined with studies on effective early intervention treatments for ASD that involve intense levels of relationship-focused social interaction, it is difficult to discount the significance of a potential role for parental behavior in mediating the symptom severity of ASD [207]. These early intervention behavioral therapies simulate parental care in many ways, and are often administered by both parents and clinicians [208-213]. Targeting maternal care in interventions for ASD patients can take full advantage of the earliest possible period for intervention, immediately postpartum, and extend treatment beyond prescribed clinical treatment sessions. Increased study of ASD and PPD may also reveal important etiological mechanisms, for example the role of OXT in social behavior deficits associated with a wide range of disorders. Transgenerational study of PPD and anxiety may reveal common epigenetic mechanisms given the complex genetic component of both disorders. With the increasing ability to identify infants likely to develop autism [214], and the potential effectiveness of very early intervention, enhancing the maternal care of ASD patients may substantially improve the quality of life of these patients.

Another potentially productive cross domain feature of PPD and ASD is the role of the gastrointestinal microbiome. The gut microbiome can mediate an array of social, anxiety related, and emotional behaviors in rodents [215] and humans [216] which may involve effects on neural development. Gut microbiome-brain interactions facilitate microbe based therapies in the treatment of multiple sclerosis and depression in rodent models [217, 218] and the adverse emotional effects of chronic fatigue syndrome and psychological distress in humans [219, 220]. Furthermore, both early life stress [221] and maternal separation [222] alter the gut-brain axis. Studies indicate that the microbiome of ASD patients is altered, and manipulating the microbiome in a mouse model of ASD through the feeding of exogenous bacteria decreases the display of aberrant anxiety associated behaviors and increases social behaviors [223]. This treatment decreases gut permeability, a common symptom in ASD, 
and it is concluded that there is a gut-microbiome-brain connection in this ASD model. A vaccine for Clostridium bootee is currently being developed to treat the GI symptoms of autism, and this treatment may have beneficial effects on behavior as well acting through central mechanisms [224]. However, it is unclear how the microbiome of ASD patients is altered. Significant determinants of GI microbiome early in life, during the time when autism develops, are method of birth [225] and breastfeeding [226]. The microbiomes of Csection and vaginally delivered offspring are significantly different, with C-section births lacking some of the bacteria found in vaginally delivered offspring. This difference is not ameliorated by breastfeeding. In addition, formula fed babies have different microbiomes compared to breastfeed babies [227]. C-sections, birth complications and suboptimal breastfeeding have all been associated with ASD [194, 198, 228]. It is postulated that the association between birth complications, breastfeeding, and ASD may be mediated through changes in gut microbiome, as mothers may transmit the negative effects of stress to the offspring through changes in vaginal microbiome and breastfeeding duration that then alter the gut microbiome and neural activity of the offspring.

Given the common etiological pathways and symptoms of PPD and anxiety and ASD, improved treatments for PPD and anxiety may be effective preventative measures for some forms of autism in the offspring of depressed mothers and future generations. However, the greatest benefit of cross domain studies on PPD and ASD may be with general improvements in social behavior in offspring exposed to PPD and anxiety.

\section{PPD AND ANXIETY AS A RISK FACTOR FOR PTSD IN OFFSPRING}

There are also increasing links between the pathophysiology of PPD and PTSD, and evidence that both of these disorders may benefit from a cross domain approach. For example, PTSD is characterized by severe anxiety, hyperarousal, hypervigilance, difficulty concentrating, sleep disturbances, re-experiencing trauma, avoidance of trauma-like situations, and dissociative amnesia, symptoms which persist long after the initial traumatic event [229, 230]. Several of these symptoms are also experienced by mothers with PPD, and an estimated $85 \%$ of PTSD patients have comorbid disorders, the most common of which are depression and substance/alcohol abuse/dependence, and other anxiety disorders [231]. In addition, several risk factors for developing PTSD have been identified, including being female, prior psychiatric illness, familial history of psychiatric illness, childhood behavioral problems, and lack of social support [229, 232-234]. Many of these risk factors are similar to those experienced by mothers with PPD and anxiety. Due to the high comorbidity between PTSD and depression and since PTSD is more common in females, the same women that are especially vulnerable to developing PPD might also be vulnerable to developing PTSD after experiencing trauma. Indeed, some researchers have demonstrated that PTSD symptomology can explain about half of the variance in postpartum depressive symptom scores [235], and suggest that PPD and PTSD may share underlying vulnerabilities. Because of the overlapping domains of both PPD and PTSD (e.g. hyperarousal; sleep disturbances; anxiety; difficulty concentrating), animal models that can specifically target and measure several of these domains may have greater clinical relevance to the underlying biological mechanisms of overlapping psychopathologies such as PPD and PTSD. 
Children may be more vulnerable to PTSD after exposure to traumatic experiences compared to adults [236]. PTSD rates as high as $38 \%$ have been reported in war-exposed children [237]. Higher rates of PTSD were found in children compared to adults exposed to the events of 9/11 on television, and maternal depression was positively associated with PTSD symptoms in these children [238]. In addition, mothers of children with PTSD were found to have less social support, to be more depressed and anxious, and have more PTSD symptoms themselves than mothers of children without PTSD [237]. This could indicate that depressed moms and their offspring that are simultaneously exposed to a traumatic event might be similarly vulnerable to developing PTSD. Further evidence from offspring of Holocaust survivors purports that maternal, but not paternal, PTSD confers increased risk of PTSD in offspring, even though increased lifetime risk of PTSD was not found in survivor offspring compared to comparison subjects overall [239]. An intergenerational relationship between mothers and their offspring has also been demonstrated by Roberts and colleagues [240]; children of women with PTSD were found to be more likely to experience traumatic events themselves, compared to children of mothers without PTSD. It is possible that the intergenerational transmission of PPD and PTSD may involve similar mechanisms.

Mothers with either PTSD or PPD may exhibit similar struggles with maternal care. For example, mothers with PTSD have impaired mother-infant bonding [241-243] similar to mothers with PPD. Schechter and colleagues [244] found that mothers with PTSD related to interpersonal violence exhibited impaired care giving to their children, and reported their child's distress at being separated from them as more stressful than controls. In these offspring, the impaired maternal care they receive is likely compounded by witnessing their mothers' traumatic interpersonal violent incident. Mothers with PTSD also display significantly more PPD symptoms than moms without PTSD [241]. Complications with childbirth itself can also be a traumatic incident that can trigger the onset of postpartum PTSD, especially in women with a history of prior traumatic pregnancies or childbirths [245, 246]. Women with PPD may be particularly vulnerable to perceiving complicated births as traumatic, since birth perceptions were demonstrated to be negatively correlated with depression scores [247]. Women with a history of multiple pregnancy losses are also more likely to have both depression and PTSD than women with a history of only one pregnancy loss [248]. Given that poor maternal behavior in infancy has recently been demonstrated to negatively affect adult mental health outcomes once the infant reaches 27-33 years of age in a 30-year prospective study of inner-city infants born in the U.S. [249], increasing maternal behavior as a domain investigated in animal models of PPD and PTSD may critical to the development of novel treatment strategies. There are also substantial mechanistic similarities between these two disorders.

While studies have produced varying results, it is generally thought that PTSD is marked by dysfunction of the HPA axis [250-253]. PTSD manifests when a normal acute stress response is unable to be contained, leading to large scale biological alterations in the HPA axis in an individual after a traumatic event. Specifically, these biological changes of the HPA axis are thought to include increased negative feedback of glucocorticoids resulting in overall decreased levels of glucocorticoids like cortisol in the affected individual [253]. Types of early life stress in humans that are much more severe than PPD, such as childhood maltreatment and abuse, are also associated with hypocortisolism and with an increased risk 
of developing PTSD in adulthood [254]. In a study by Yehuda and colleagues [255], children that had experienced emotional abuse had lower cortisol levels than those without emotional abuse experience, especially in children with PTSD. Although maltreatment and abuse rarely coincide with PPD, any early life experience that produces similar changes in HPA axis function may also increase risk of adult PTSD in offspring. Although depression in general is thought to be marked by hypercortisolemia, Harris and colleagues [256] found lower evening cortisol levels in women who had developed depression by 5-6 weeks postpartum compared to those women who hadn't developed depression. Furthermore, O'Donnell and colleagues [257] found that maternal antepartum mood was associated with altered diurnal cortisol in 15 year old children of affected mothers, suggesting intergenerational transmission of HPA axis alterations associated with PPD. However, cortisol awakening responses of healthy women during pregnancy (38 weeks), but not during lactation (6 weeks postpartum) were associated with HPA axis responses to a psychosocial stress test given at 8 weeks postpartum, suggesting that HPA axis activity during pregnancy is a better predictor of postpartum stress reactivity than HPA axis activity during lactation itself [258]. In addition, Essex and colleagues [259] found lower cortisol levels in adolescents (age 15) exposed to high maternal depression, although this relationship changed if children exhibited symptoms of mental illness themselves. Other studies have related inconsistent parenting with changes in cortisol variability [260] and higher maternal psychopathology with lower, and more unstable evening cortisol levels in children of adoptive parents, importantly suggesting non-genetic, environmental influences on HPA axis functioning and stress reactivity in children. It is postulated that women with PPD confer an increased risk of mental illnesses such as PTSD to their children by altering HPA axis function in infancy.

Evidence from both animal [261-264] and human [230, 255, 259, 260, 265-268] studies point to dysregulation of the HPA axis in the link between severe forms of early life adversity and stress reactivity later in life. In humans, experiencing trauma as a child can have complex effects on HPA axis function; Weems and Carrion [269] observed a significant positive relationship between PTSD symptoms and cortisol levels in children after recent trauma (within 12 months), but a negative association in these endpoints after more distal trauma exposure (occurring more than one year ago). Recent studies have investigated the potential that severe forms of early life adversity increase a child's vulnerability for HPA axis dysfunction and PTSD through epigenetic mechanisms [270272]. While these types of ELS are not typically experienced by children of mothers with PPD and anxiety, there is perhaps a similar role for epigenetics in conferred risk of adult mental illness in children of mothers with PPD and anxiety. Animal models that offer more translational relevance to early life impaired maternal care, such as early life CSS, are critically needed to understand exactly how epigenetic changes occurring through early life experience may affect stress reactivity in adulthood. This may then lead to discoveries on the underlying transgenerational mechanisms of psychopathologies like PPD and PTSD. Although no clinical evidence to date has specifically examined adult risk of PTSD in children of mothers with PPD and anxiety, this topic warrants attention, and may lead to valuable connections between the underlying biological mechanisms of these disorders. 


\section{SUMMARY}

Stress associated depression and anxiety, most commonly comorbid in the pregnant mother, have adverse effects on several domains in the offspring which serve as risk factors for, or represent the earliest manifestation of later stress-evoked psychopathology. In addition, the clinical literature supports the hypothesis that depression and anxiety occurring in the postpartum period also have adverse effects on several domains of offspring physical and mental health. The best studied of these domains include: arousal, cognition, social processing and negative valence, however they are usually studied independently of each other. Combining multiple domains may be more clinically representative than individual study. In addition, while clinical studies have focused on the adverse effects of PPD and anxiety on the infant/child, the mechanisms for these effects have not been thoroughly studied in humans. Constructs or domains studied in both human neurodevelopment and adult psychopathology (e.g. temperament, cognition, arousal, social behavior etc.), are more compatible to cross domain mechanistic studies in animal models. Cross domain research studies in animal models are therefore ideal for the investigation of specific mechanisms involved in PPD and anxiety, and the effects these disorders have on offspring. The key to increasing the cross domain component of psychiatric research may be to promote more bidirectional interaction between the fields of behavioral ecology, molecular behavioral neuroscience, and clinical psychiatry. Multiple types of clinical observations need to be carefully considered in the development of animal and human studies aimed at identifying mechanisms, treatments, and preventative measures.

\section{CONCLUSIONS and FUTURE DIRECTIONS}

When possible, it is preferable to prevent rather than treat psychiatric disorders. It is suggested that an increase in integrated cross domain studies of PPD and anxiety may identify valuable targets for safe and effective preventative measures for neurodevelopmental changes and the risk of depression, anxiety, ASD, and PTSD in offspring of affected mothers. While addressing psychiatric symptoms in mothers is a primary concern for clinicians and researchers, cross domain focus on potential difficulties in the mother and offspring may yield substantial preventative benefits for both the children of depressed and anxious women and future generations. It has been argued here that cross domain research on PPD will benefit from greater ethological relevance in animal work, interdisciplinary longitudinal clinical studies, and general increases in direct communication and collaboration between animal and clinical researchers. One key objective of an increase in communication is to stimulate reverse translational projects that bring novel clinical observations back to animal models for detailed mechanistic study. A major clinical need is to assess multiple symptoms across the lifespan in developing treatment plans for these disorders as well in the long-term evaluation of the effectiveness of these treatments. In animal studies, the major needs are increased construct validity in model development and the consideration of a more specific timing, and broader range, of symptoms. Increased cross domain research on postpartum depression and anxiety in animals and humans both within and between disorders will result in more effective preventative translation for depression, anxiety, autism, PTSD, and a multitude of other disorders associated with stress induced impairments in maternal functioning. 


\section{References}

1. Vesga-Lopez O, et al. Psychiatric disorders in pregnant and postpartum women in the United States. Archives of general psychiatry. 2008; 65(7):805-15. [PubMed: 18606953]

2. Earls MF. Incorporating recognition and management of perinatal and postpartum depression into pediatric practice. Pediatrics. 2010; 126(5):1032-9. [PubMed: 20974776]

3. Gavin NI, et al. Perinatal depression: a systematic review of prevalence and incidence. Obstet Gynecol. 2005; 106(5 Pt 1):1071-83. [PubMed: 16260528]

4. Gotlib IH, et al. Prospective investigation of postpartum depression: factors involved in onset and recovery. Journal of abnormal psychology. 1991; 100(2):122-32. [PubMed: 2040762]

5. Lindahl V, Pearson JL, Colpe L. Prevalence of suicidality during pregnancy and the postpartum. Arch Womens Ment Health. 2005; 8(2):77-87. [PubMed: 15883651]

6. Borri C, et al. Axis I psychopathology and functional impairment at the third month of pregnancy: Results from the Perinatal Depression-Research and Screening Unit (PND-ReScU) study. J Clin Psychiatry. 2008; 69(10):1617-24. [PubMed: 19192445]

7. Reck C, et al. Prevalence, onset and comorbidity of postpartum anxiety and depressive disorders. Acta Psychiatr Scand. 2008; 118(6):459-68. [PubMed: 18840256]

8. Matthey $\mathrm{S}$, et al. Diagnosing postpartum depression in mothers and fathers: whatever happened to anxiety? Journal of Affective Disorders. 2003; 74(2):139-147. [PubMed: 12706515]

9. Logsdon MC, Wisner K, Hanusa BH. Does maternal role functioning improve with antidepressant treatment in women with postpartum depression? Journal of Women's Health. 2009; 18(1):85-90.

10. Murray L, et al. The impact of postnatal depression and associated adversity on early mother-infant interactions and later infant outcome. Child Development. 1996; 67(5):2512-26. [PubMed: 9022253]

11. Field T. Postpartum depression effects on early interactions, parenting, and safety practices: a review. Infant behavior \& development. 2010; 33(1):1-6. [PubMed: 19962196]

12. Beck CT. The effects of postpartum depression on maternal-infant interaction: a meta-analysis. Nursing Research. 1995; 44(5):298-304. [PubMed: 7567486]

13. Cohn JF, et al. Face-to-face interactions of postpartum depressed and nondepressed mother-infant pairs at 2 months. Developmental Psychology. 1990; 26(1):15-23.

14. Goodman S, et al. Maternal depression and child psychopathology: A meta-analytic review. Clinical Child and Family Psychology Review. 2011; 14(1):1-27. [PubMed: 21052833]

15. Reck C, et al. Interactive regulation of affect in postpartum depressed mothers and their infants: an overview. Psychopathology. 2004; 37(6):272-80. [PubMed: 15539778]

16. Ambrosini A, Donzelli G, Stanghellini G. Early perinatal diagnosis of mothers at risk of developing post-partum depression - a concise guide for obstetricians, midwives, neonatologists and paediatricians. Journal of Maternal-Fetal and Neonatal Medicine. 2012; 25(7):1096-1101. [PubMed: 21919554]

17. Walker M, et al. Reported Maternal Postpartum Depression and Risk of Childhood Psychopathology. Maternal and Child Health Journal. 2013; 17(5):907-917. [PubMed: 22744292]

18. Letourneau NL, et al. Postpartum depression is a family affair: Addressing the impact on mothers, fathers, and children. Issues in mental health nursing. 2012; 33(7):445-57. [PubMed: 22757597]

19. Bernstein IH, et al. Symptom features of postpartum depression: are they distinct? Depression and anxiety. 2008; 25(1):20-6. [PubMed: 17187349]

20. Chen $\mathrm{HH}$, et al. The interrelationships among acculturation, social support, and postpartum depression symptoms among marriage-based immigrant women in taiwan: A cohort study. Journal of immigrant and minority health/Center for Minority Public Health. 2012

21. Cutrona CE, Troutman BR. Social support, infant temperament, and parenting self-efficacy: a mediational model of postpartum depression. Child Development. 1986; 57(6):1507-18. [PubMed: 3802975]

22. Letourneau N, Duffett-Leger L, Salmani M. The role of paternal support in the behavioural development of children exposed to postpartum depression. The Canadian journal of nursing 
research $=$ Revue canadienne de recherche en sciences infirmieres. 2009; 41(3):86-106. [PubMed: 19831056]

23. Logsdon MC, McBride AB, Birkimer JC. Social support and postpartum depression. Research in nursing \& health. 1994; 17(6):449-57. [PubMed: 7972923]

24. Yagmur Y, Ulukoca N. Social support and postpartum depression in low-socioeconomic level postpartum women in Eastern Turkey. International journal of public health. 2010; 55(6):543-9. [PubMed: 20725761]

25. Haga SM, et al. A longitudinal study of postpartum depressive symptoms: multilevel growth curve analyses of emotion regulation strategies, breastfeeding self-efficacy, and social support. Archives of Women's Mental Health. 2012; 15(3):175-84.

26. Steube AM, et al. Failed lactation and perinatal depression: Common problems with shared neuroendocrine mechanism. J Women's Health. 2011; 21(3):264-272.

27. Dennis CL, McQueen K. The relationship between infant-feeding outcomes and postpartum depression: a qualitative systematic review. Pediatrics. 2009; 123(4):e736-51. [PubMed: 19336362]

28. Bloch M, Daly R, Rubinow D. Endocrine factors in the etiology of postpartum depression. Compr Psychiatry. 2003; 44(3):234-246. [PubMed: 12764712]

29. Bloch M, et al. Effects of gonadal steroids in women with a history of postpartum depression. The American journal of psychiatry. 2000; 157(6):924-30. [PubMed: 10831472]

30. Garcia-Esteve L, et al. Family caregiver role and premenstrual syndrome as associated factors for postnatal depression. Archives of Women's Mental Health. 2008; 11(3):193-200.

31. Freeman EW. Treatment of depression associated with the menstrual cycle: premenstrual dysphoria, postpartum depression, and the perimenopause. Dialogues in clinical neuroscience. 2002; 4(2):177-91. [PubMed: 22033555]

32. Chen TH, et al. Prevalence of depressive and anxiety disorders in an assisted reproductive technique clinic. Human Reproduction. 2004; 19(10):2313-2318. [PubMed: 15242992]

33. Monti F, et al. Depressive symptoms during late pregnancy and early parenthood following assisted reproductive technology. Fertility and Sterility. 2009; 91(3):851-857. [PubMed: 18314111]

34. NIMH Research Domain Criteria (RDoC) 2011. Jan 27. 2014 ]; Available from: http:// www.nimh.nih.gov/research-priorities/rdoc/nimh-research-domain-criteria-rdoc.shtml

35. Monk C, Spicer J, Champagne FA. Linking prenatal maternal adversity to developmental outcomes in infants: the role of epigenetic pathways. Dev Psychopathol. 2012; 24(4):1361-76. [PubMed: 23062303]

36. Goldstein, JM.; Handa, RJ.; Tobet, SA. Disruption of fetal hormonal programming (prenatal stress) implicates shared risk for sex differences in depression and cardiovascular disease. Front Neuroendocrinol; 2013.

37. Kalueff AV, et al. Domain interplay concept in animal models of neuropsychiatric disorders: A new strategy for high-throughput neurophenotyping research. Behavioural Brain Research. 2008; 188(2):243-249. [PubMed: 18164476]

38. Hendrie C, Pickles A. The failure of the antidepressant drug discovery process is systemic. Journal of Psychopharmacology. 2012

39. Barbui C, et al. Efficacy of antidepressants and benzodiazepines in minor depression: systematic review and meta-analysis. The British Journal of Psychiatry. 2011; 198(1):11-16. [PubMed: 21200071]

40. Fournier JC, et al. Antidepressant drug effects and depression severity: A patient-level metaanalysis. JAMA. 2010; 303(1):47-53. [PubMed: 20051569]

41. Nolen-Hoeksema S. Gender Differences in Depression. Current Directions in Psychological Science. 2001; 10(5):173-176.

42. Nephew BC, Bridges RS. Effects of chronic social stress during lactation on maternal behavior and growth in rats. Stress. 2011; 14(6):677-684. [PubMed: 21875305]

43. Carini LM, Murgatroyd CA, Nephew BC. Using chronic social stress to model postpartum depression in lactating rodents. J Vis Exp. 2013; 76:e50324. [PubMed: 23792810] 
44. Babb JA, et al. Transgenerational effects of social stress on social behavior, corticosterone, oxytocin, and prolactin in rats. Horm Behav. 2014 in press.

45. Murgatroyd CA, Nephew BC. Effects of early life social stress on maternal behavior and neuroendocrinology. Psychoneuroendocrinology. 2013; 38(2):219-228. [PubMed: 22770862]

46. Carini LM, Nephew BC. Effects of early life social stress on endocrinology, maternal behavior, and lactation in rats. Hormones and Behavior. 2013; 64(4):634-641. [PubMed: 24005186]

47. Blanchard RJ, McKittrick CR, Blanchard DC. Animal models of social stress: effects on behavior and brain neurochemical systems. Physiology \& Behavior. 2001; 73(3):261-271. [PubMed: 11438351]

48. Mattson BJ, et al. Comparison of two positive reinforcing stimuli: pups and cocaine throughout the postpartum period. Behav Neurosci. 2001; 115:683-694. [PubMed: 11439457]

49. Coyer SM. Women in recovery discuss parenting while addicted to cocaine. MCN Am J Matern Child Nurs. 2003; 28:45-49. [PubMed: 12514356]

50. Coyer SM. Mothers Recovering From Cocaine Addiction: Factors Affecting Parenting Skills. Journal of Obstetric, Gynecologic, \& Neonatal Nursing. 2001; 30(1):71-79.

51. Carten AJ. Mothers in recovery: rebuilding families in the aftermath of addiction. Social Work. 1996; 41(2):214-223. [PubMed: 8851362]

52. O'Connor TG, Heron J, Glover V. Antenatal anxiety predicts child behavioral/emotional problems independently of postnatal depression. Journal of the American Academy of Child and Adolescent Psychiatry. 2002; 41(12):1470-7. [PubMed: 12447034]

53. Van den Bergh BRH, Marcoen A. High Antenatal Maternal Anxiety Is Related to ADHD Symptoms, Externalizing Problems, and Anxiety in 8- and 9-Year-Olds. Child Development. 2004; 75(4):1085-1097. [PubMed: 15260866]

54. Matthews S, Phillips D. Transgenerational inheritance of stress pathology. Exp Neurol. 2012; 233:95-101. [PubMed: 21281632]

55. Glasheen C, et al. Exposure to maternal pre- and postnatal depression and anxiety symptoms: Risk for major depression, anxiety disorders, and conduct disorder in adolescent offspring. Development and Psychopathology. 2013; 25(4pt1):1045-1063. [PubMed: 24229548]

56. Katz SJ, Hammen CL, Brennan PA. Maternal depression and the intergenerational transmission of relational impairment. Journal of Family Psychology. 2013; 27(1):86-95. [PubMed: 23421836]

57. Herba CM, et al. Maternal depressive symptoms and children's emotional problems: Can early child care help children of depressed mothers? JAMA Psychiatry. 2013; 70(8):830-838. [PubMed: 23784556]

58. Nilsen W, et al. Pathways from Maternal Distress and Child Problem Behavior to Adolescent Depressive Symptoms: A Prospective Examination from Early Childhood to Adolescence. Journal of Developmental \& Behavioral Pediatrics. 2013; 34(5):303-313.10.1097/DBP. 0b013e318293ab05 [PubMed: 23751885]

59. Raposa E, et al. The Long-Term Effects of Maternal Depression: Early Childhood Physical Health as a Pathway to Offspring Depression. Journal of Adolescent Health. 2014; 54(1):88-93. [PubMed: 24060574]

60. Lobel M, et al. Pregnancy-specific stress, prenatal health behaviors, and birth outcomes. Health Psychol. 2008; 27(5):604-15. [PubMed: 18823187]

61. Rondo PH, et al. Maternal psychological stress and distress as predictors of low birth weight, prematurity and intrauterine growth retardation. Eur J Clin Nutr. 2003; 57(2):266-72. [PubMed: 12571658]

62. Wadhwa PD, et al. The association between prenatal stress and infant birth weight and gestational age at birth: a prospective investigation. American Journal of Obstetrics and Gynecology. 1993; 169(4):858-65. [PubMed: 8238139]

63. Bodnar LM, et al. Prepregnancy body mass index, gestational weight gain, and the likelihood of major depressive disorder during pregnancy. Journal of Clinical Psychiatry. 2009; 70(9):1290-6. [PubMed: 19607761]

64. Cripe SM, et al. Risk of preterm delivery and hypertensive disorders of pregnancy in relation to maternal co-morbid mood and migraine disorders during pregnancy. Paediatr Perinat Epidemiol. 2011; 25(2):116-23. [PubMed: 21281324] 
65. Wisner KL, et al. Risk-benefit decision making for treatment of depression during pregnancy. American Journal of Psychiatry. 2000; 157(12):1933-40. [PubMed: 11097953]

66. Grote NK, et al. A meta-analysis of depression during pregnancy and the risk of preterm birth, low birth weight, and intrauterine growth restriction. Arch Gen Psychiatry. 2010; 67(10):1012-24. [PubMed: 20921117]

67. Istvan J. Stress, anxiety, and birth outcomes: a critical review of the evidence. Psychological Bulletin. 1986; 100(3):331-48. [PubMed: 3797559]

68. Qiao Y, Wang J, Li J. Effects of depressive and anxiety symptoms during pregnancy on pregnant, obstetric and neonatal outcomes: a follow-up study. J Obstet Gynaecol. 2012; 32(3):237-40. [PubMed: 22369395]

69. Chung TK, et al. Antepartum depressive symptomatology is associated with adverse obstetric and neonatal outcomes. Psychosom Med. 2001; 63(5):830-4. [PubMed: 11573032]

70. Jablensky AV, et al. Pregnancy, delivery, and neonatal complications in a population cohort of women with schizophrenia and major affective disorders. Am J Psychiatry. 2005; 162(1):79-91. [PubMed: 15625205]

71. Steer RA, et al. Self-reported depression and negative pregnancy outcomes. J Clin Epidemiol. 1992; 45(10):1093-9. [PubMed: 1474405]

72. Van den Bergh BR, et al. Antenatal maternal anxiety and stress and the neurobehavioural development of the fetus and child: links and possible mechanisms. A review. Neurosci Biobehav Rev. 2005; 29(2):237-58. [PubMed: 15811496]

73. Kinsella MT, Monk C. Impact of maternal stress, depression and anxiety on fetal neurobehavioral development. Clin Obstet Gynecol. 2009; 52(3):425-40. [PubMed: 19661759]

74. Davis EP, et al. Corticotropin-releasing hormone during pregnancy is associated with infant temperament. Dev Neurosci. 2005; 27(5):299-305. [PubMed: 16137987]

75. Davis EP, et al. Effects of prenatal betamethasone exposure on regulation of stress physiology in healthy premature infants. Psychoneuroendocrinology. 2004; 29(8):1028-36. [PubMed: 15219654]

76. Davis EP, et al. Prenatal exposure to maternal depression and cortisol influences infant temperament. J Am Acad Child Adolesc Psychiatry. 2007; 46(6):737-46. [PubMed: 17513986]

77. Nasreen HE, et al. Impact of maternal depressive symptoms and infant temperament on early infant growth and motor development: results from a population based study in Bangladesh. J Affect Disord. 2013; 146(2):254-61. [PubMed: 23063237]

78. Huizink AC, et al. Psychological measures of prenatal stress as predictors of infant temperament. J Am Acad Child Adolesc Psychiatry. 2002; 41(9):1078-85. [PubMed: 12218429]

79. Huizink AC, et al. Stress during pregnancy is associated with developmental outcome in infancy. $\mathbf{J}$ Child Psychol Psychiatry. 2003; 44(6):810-8. [PubMed: 12959490]

80. Wadhwa PD, Sandman CA, Garite TJ. The neurobiology of stress in human pregnancy: implications for prematurity and development of the fetal central nervous system. Prog Brain Res. 2001; 133:131-42. [PubMed: 11589126]

81. Evans LM, Myers MM, Monk C. Pregnant women's cortisol is elevated with anxiety and depression - but only when comorbid. Arch Womens Ment Health. 2008; 11(3):239-48. [PubMed: 18493710]

82. Davis EP, et al. Prenatal maternal stress programs infant stress regulation. J Child Psychol Psychiatry. 2011; 52(2):119-29. [PubMed: 20854366]

83. Bergman K, et al. Maternal prenatal cortisol and infant cognitive development: moderation by infant-mother attachment. Biol Psychiatry. 2010; 67(11):1026-32. [PubMed: 20188350]

84. Bergman K, et al. Maternal stress during pregnancy predicts cognitive ability and fearfulness in infancy. J Am Acad Child Adolesc Psychiatry. 2007; 46(11):1454-63. [PubMed: 18049295]

85. Brennan PA, et al. Maternal depression and infant cortisol: influences of timing, comorbidity and treatment. J Child Psychol Psychiatry. 2008; 49(10):1099-107. [PubMed: 18492036]

86. Diego MA, et al. Prepartum, postpartum, and chronic depression effects on newborns. Psychiatry. 2004; 67(1):63-80. [PubMed: 15139586] 
87. Field T, et al. Prenatal maternal biochemistry predicts neonatal biochemistry. Int J Neurosci. 2004; 114(8):933-45. [PubMed: 15527200]

88. Davidson RJ. Affective style, psychopathology, and resilience: brain mechanisms and plasticity. Am Psychol. 2000; 55(11):1196-214. [PubMed: 11280935]

89. Cole PM, et al. Individual differences in emotion regulation and behavior problems in preschool children. J Abnorm Psychol. 1996; 105(4):518-29. [PubMed: 8952185]

90. Hayes LJ, Goodman SH, Carlson E. Maternal antenatal depression and infant disorganized attachment at 12 months. Attach Hum Dev. 2013; 15(2):133-53. [PubMed: 23216358]

91. Koutra K, et al. Antenatal and postnatal maternal mental health as determinants of infant neurodevelopment at 18 months of age in a mother-child cohort (Rhea Study) in Crete, Greece. Soc Psychiatry Psychiatr Epidemiol. 2013; 48(8):1335-45. [PubMed: 23248031]

92. Gerardin P, et al. Depression during pregnancy: is the developmental impact earlier in boys? A prospective case-control study. J Clin Psychiatry. 2011; 72(3):378-87. [PubMed: 21208585]

93. Beydoun H, Saftlas AF. Physical and mental health outcomes of prenatal maternal stress in human and animal studies: a review of recent evidence. Paediatr Perinat Epidemiol. 2008; 22(5):438-66. [PubMed: 18782252]

94. Barker ED, et al. The contribution of prenatal and postnatal maternal anxiety and depression to child maladjustment. Depress Anxiety. 2011; 28(8):696-702. [PubMed: 21769997]

95. Glover V, et al. Antenatal maternal anxiety is linked with atypical handedness in the child. Early Hum Dev. 2004; 79(2):107-18. [PubMed: 15324991]

96. Van den Bergh BR, Marcoen A. High antenatal maternal anxiety is related to ADHD symptoms, externalizing problems, and anxiety in 8- and 9-year-olds. Child Dev. 2004; 75(4):1085-97. [PubMed: 15260866]

97. Van den Bergh BR, et al. High antenatal maternal anxiety is related to impulsivity during performance on cognitive tasks in 14- and 15-year-olds. Neurosci Biobehav Rev. 2005; 29(2):25969. [PubMed: 15811497]

98. Buss C, et al. Maternal pregnancy-specific anxiety is associated with child executive function at 69 years age. Stress. 2011; 14(6):665-76. [PubMed: 21995526]

99. Buss C, et al. High pregnancy anxiety during mid-gestation is associated with decreased gray matter density in 6-9-year-old children. Psychoneuroendocrinology. 2010; 35(1):141-53. [PubMed: 19674845]

100. Britton JR. Infant temperament and maternal anxiety and depressed mood in the early postpartum period. Women Health. 2011; 51(1):55-71. [PubMed: 21391161]

101. Feldman R, et al. Maternal depression and anxiety across the postpartum year and infant social engagement, fear regulation, and stress reactivity. J Am Acad Child Adolesc Psychiatry. 2009; 48(9):919-27. [PubMed: 19625979]

102. Forman DR, et al. Effective treatment for postpartum depression is not sufficient to improve the developing mother-child relationship. Development and Psychopathology. 2007; 19(2):585-602. [PubMed: 17459185]

103. Deave T, et al. The impact of maternal depression in pregnancy on early child development. BJOG. 2008; 115(8):1043-51. [PubMed: 18651886]

104. Sohr-Preston SL, Scaramella LV. Implications of timing of maternal depressive symptoms for early cognitive and language development. Clin Child Fam Psychol Rev. 2006; 9(1):65-83. [PubMed: 16817009]

105. Downey G, Coyne JC. Children of depressed parents: an integrative review. Psychological Bulletin. 1990; 108(1):50-76. [PubMed: 2200073]

106. Murray L. The impact of postnatal depression on infant development. J Child Psychol Psychiatry. 1992; 33(3):543-61. [PubMed: 1577898]

107. Azak S. Maternal depression and sex differences shape the infants' trajectories of cognitive development. Infant Behav Dev. 2012; 35(4):803-14. [PubMed: 22982282]

108. Sharp D, et al. The impact of postnatal depression on boys' intellectual development. J Child Psychol Psychiatry. 1995; 36(8):1315-36. [PubMed: 8988269] 
109. Kurstjens S, Wolke D. Effects of maternal depression on cognitive development of children over the first 7 years of life. J Child Psychol Psychiatry. 2001; 42(5):623-36. [PubMed: 11464967]

110. Pilowsky DJ, et al. Children of currently depressed mothers: a STAR*D ancillary study. J Clin Psychiatry. 2006; 67(1):126-36. [PubMed: 16426099]

111. Murray L, et al. The socioemotional development of 5-year-old children of postnatally depressed mothers. J Child Psychol Psychiatry. 1999; 40(8):1259-71. [PubMed: 10604404]

112. Philipps LH, O'Hara MW. Prospective study of postpartum depression: 4 1/2-year follow-up of women and children. J Abnorm Psychol. 1991; 100(2):151-5. [PubMed: 2040765]

113. Murray L, et al. Maternal postnatal depression and the development of depression in offspring up to 16 years of age. J Am Acad Child Adolesc Psychiatry. 2011; 50(5):460-70. [PubMed: 21515195]

114. Korhonen M, et al. A longitudinal study of maternal prenatal, postnatal and concurrent depressive symptoms and adolescent well-being. J Affect Disord. 2012; 136(3):680-92. [PubMed: 22036793]

115. Goodman SH, et al. Maternal depression and child psychopathology: a meta-analytic review. Clin Child Fam Psychol Rev. 2011; 14(1):1-27. [PubMed: 21052833]

116. Verbeek T, et al. Postpartum depression predicts offspring mental health problems in adolescence independently of parental lifetime psychopathology. J Affect Disord. 2012; 136(3):948-54. [PubMed: 21930302]

117. Brennan PA, et al. Chronicity, severity, and timing of maternal depressive symptoms: relationships with child outcomes at age 5. Dev Psychol. 2000; 36(6):759-66. [PubMed: 11081699]

118. Vliegen N, Casalin S, Luyten P. The course of postpartum depression: a review of longitudinal studies. Harv Rev Psychiatry. 2014; 22(1):1-22. [PubMed: 24394219]

119. Hanley GE, Brain U, Oberlander TF. Infant developmental outcomes following prenatal exposure to antidepressants, and maternal depressed mood and positive affect. Early Hum Dev. 2013; 89(8):519-24. [PubMed: 23384962]

120. Glover V, Hill J. Sex differences in the programming effects of prenatal stress on psychopathology and stress responses: an evolutionary perspective. Physiol Behav. 2012; 106(5): 736-40. [PubMed: 22353310]

121. Godfrey KM, et al. Epigenetic mechanisms and the mismatch concept of the developmental origins of health and disease. Pediatr Res. 2007; 61(5 Pt 2):5R-10R.

122. Glover V. Maternal stress or anxiety in pregnancy and emotional development of the child. Br J Psychiatry. 1997; 171:105-6. [PubMed: 9337941]

123. O'Donnell KJ, et al. Maternal prenatal anxiety and downregulation of placental 11 beta-HSD2. Psychoneuroendocrinology. 2012; 37(6):818-26. [PubMed: 22001010]

124. Mairesse J, et al. Maternal stress alters endocrine function of the feto-placental unit in rats. Am $\mathbf{J}$ Physiol Endocrinol Metab. 2007; 292(6):E1526-33. [PubMed: 17264224]

125. Clifton VL. Review: Sex and the human placenta: mediating differential strategies of fetal growth and survival. Placenta. 2010; 31(Suppl):S33-9. [PubMed: 20004469]

126. Bale TL. Is mom too sensitive? Impact of maternal stress during gestation. Front Neuroendocrinol. 2005; 26(1):41-9. [PubMed: 15862184]

127. Maccari S, et al. Prenatal stress and long-term consequences: implications of glucocorticoid hormones. Neurosci Biobehav Rev. 2003; 27(1-2):119-27. [PubMed: 12732228]

128. Owen D, Andrews MH, Matthews SG. Maternal adversity, glucocorticoids and programming of neuroendocrine function and behaviour. Neurosci Biobehav Rev. 2005; 29(2):209-26. [PubMed: 15811494]

129. Essex MJ, et al. Epigenetic vestiges of early developmental adversity: childhood stress exposure and DNA methylation in adolescence. Child Dev. 2013; 84(1):58-75. [PubMed: 21883162]

130. Uddin M, et al. Sex differences in DNA methylation may contribute to risk of ptsd and depression: a review of existing evidence. Depress Anxiety. 2013; 30(12):1151-60. [PubMed: 23959810] 
131. Mulder EJ, et al. Prenatal maternal stress: effects on pregnancy and the (unborn) child. Early Hum Dev. 2002; 70(1-2):3-14. [PubMed: 12441200]

132. Davis EP, Waffarn F, Sandman CA. Prenatal treatment with glucocorticoids sensitizes the hpa axis response to stress among full-term infants. Dev Psychobiol. 2011; 53(2):175-83. [PubMed: 21298632]

133. Oberlander TF, et al. Prenatal exposure to maternal depression, neonatal methylation of human glucocorticoid receptor gene (NR3C1) and infant cortisol stress responses. Epigenetics. 2008; 3(2):97-106. [PubMed: 18536531]

134. Devlin AM, et al. Prenatal exposure to maternal depressed mood and the MTHFR C677T variant affect SLC6A4 methylation in infants at birth. PLoS One. 2010; 5(8):e12201. [PubMed: 20808944]

135. Ronsaville DS, et al. Maternal and environmental factors influence the hypothalamic-pituitaryadrenal axis response to corticotropin-releasing hormone infusion in offspring of mothers with or without mood disorders. Dev Psychopathol. 2006; 18(1):173-94. [PubMed: 16478558]

136. Sandman CA, et al. Exposure to prenatal psychobiological stress exerts programming influences on the mother and her fetus. Neuroendocrinology. 2012; 95(1):7-21. [PubMed: 21494029]

137. Pilowsky DJ, et al. Family discord, parental depression, and psychopathology in offspring: 20year follow-up. J Am Acad Child Adolesc Psychiatry. 2006; 45(4):452-60. [PubMed: 16601650]

138. Dawson G, et al. Preschool outcomes of children of depressed mothers: role of maternal behavior, contextual risk, and children's brain activity. Child Dev. 2003; 74(4):1158-75. [PubMed: 12938711]

139. Bogels SM, Brechman-Toussaint ML. Family issues in child anxiety: attachment, family functioning, parental rearing and beliefs. Clin Psychol Rev. 2006; 26(7):834-56. [PubMed: 16473441]

140. McLeod BD, Wood JJ, Weisz JR. Examining the association between parenting and childhood anxiety: a meta-analysis. Clin Psychol Rev. 2007; 27(2):155-72. [PubMed: 17112647]

141. Naumova OY, et al. Differential patterns of whole-genome DNA methylation in institutionalized children and children raised by their biological parents. Dev Psychopathol. 2012; 24(1):143-55. [PubMed: 22123582]

142. Zerhouni EA. US biomedical research: basic, translational, and clinical sciences. JAMA. 2005; 294(11):1352-8. [PubMed: 16174693]

143. McArthur R, Borsini F. What do you mean by “Translational Research?” An enquiry though animal and translational models for CNS drug discovery: Psychiatric disorders. Animal and translational models for CNS drug discovery. 2008; 1:xvii-xxxviii.

144. Belzung C, Lemoine M. Criteria of validity for animal models of psychiatric disorders: focus on anxiety disorders and depression. Biology of Mood \& Anxiety Disorders. 2011; 1(1):1-14. [PubMed: 22738418]

145. Malkesman O, et al. Reverse translational strategies for developing animal models of bipolar disorder. Disease Models \& Mechanisms. 2009; 2(5-6):238-245. [PubMed: 19407332]

146. Santarelli L, et al. Requirement of Hippocampal Neurogenesis for the Behavioral Effects of Antidepressants. Science. 2003; 301(5634):805-809. [PubMed: 12907793]

147. Surget A, et al. Drug-dependent requirement of hippocampal neurogenesis in a model of depression and of antidepressant reversal. Biological Psychiatry. 2008; 64(4):293-301. [PubMed: 18406399]

148. Surget A, et al. Antidepressants recruit new neurons to improve stress response regulation. Mol Psychiatry. 2011; 16(12):1177-1188. [PubMed: 21537331]

149. Boldrini M, et al. Antidepressants increase neural progenitor cells in the human hippocampus. Neuropsychopharmacology. 2009; 34:2376-2389. [PubMed: 19606083]

150. Lucassen PJ, et al. Decreased numbers of progenitor cells but no response to antidepressant drugs in the hippocampus of elderly depressed patients. Neuropharmacology. 2010; 58:940-949. [PubMed: 20138063]

151. Domingos da Silveira da Luz AC, et al. Translational Findings on Brain-Derived Neurotrophic Factor and Anxiety: Contributions from Basic Research to Clinical Practice. Neuropsychobiology. 2013; 68(3):129-138. [PubMed: 24051499] 
152. Murgatroyd C, Spengler D. Epigenetics of early child development. Frontiers in psychiatry/ Frontiers Research Foundation. 2011; 2:16.

153. Murgatroyd C, et al. Dynamic DNA methylation programs persistent adverse effects of early-life stress. Nature neuroscience. 2009; 12(12):1559-66.

154. Meaney MJ, Szyf M, Seckl JR. Epigenetic mechanisms of perinatal programming of hypothalamic-pituitary-adrenal function and health. Trends in Molecular Medicine. 2007; 13(7): 269-277. [PubMed: 17544850]

155. O'Connor TG, et al. Maternal antenatal anxiety and behavioural/emotional problems in children: a test of a programming hypothesis. Journal of Child Psychology and Psychiatry. 2003; 44(7): 1025-1036. [PubMed: 14531585]

156. Kajantie E, Räikkönen K. Early life predictors of the physiological stress response later in life. Neuroscience \& Biobehavioral Reviews. 2010; 35(1):23-32. [PubMed: 19931557]

157. Vallée M, et al. Long-term effects of prenatal stress and postnatal handling on age-related glucocorticoid secretion and cognitive performance: a longitudinal study in the rat. European Journal of Neuroscience. 1999; 11(8):2906-2916. [PubMed: 10457187]

158. Koehl M, et al. Long term neurodevelopmental and behavioral effects of perinatal life events in rats. Neurotox Res. 2001; 3(1):65-83. [PubMed: 15111262]

159. Weinstock M. The long-term behavioural consequences of prenatal stress. Neurosci Biobehav Rev. 2008; 32:1073-86. [PubMed: 18423592]

160. de Bruijn ATCE, et al. Prenatal maternal emotional complaints are associated with cortisol responses in toddler and preschool aged girls. Developmental Psychobiology. 2009; 51(7):553563. [PubMed: 19688770]

161. Davis EP, et al. Prenatal exposure to maternal depression and cortisol influences infant temperament. Journal of the American Academy of Child and Adolescent Psychiatry. 2007; 46(6):737-46. [PubMed: 17513986]

162. Seckl, JR. Glucocorticoids, developmental 'programming' and the risk of affective dysfunction. In: Ronald De Kloet, MSOE.; Eric, V., editors. Progress in Brain Research. Elsevier; 2007. p. 17-34.

163. Sharp H, et al. Frequency of infant stroking reported by mothers moderates the effect of prenatal depression on infant behavioural and physiological outcomes. PLoS ONE. 2012; 7:e45446. [PubMed: 23091594]

164. Bullinger AF, et al. Different social motives in the gestural communication of chimpanzees and human children. Developmental Science. 2011; 14(1):58-68. [PubMed: 21159088]

165. McElwain NL, Booth-LaForce C. Maternal sensitivity to infant distress and nondistress as predictors of infant-mother attachment security. Journal of Family Psychology. 2006; 20(2):247255. [PubMed: 16756400]

166. Weaver IC, et al. Epigenetic programming by maternal behavior. Nat Neurosci. 2004; 7:847-854. [PubMed: 15220929]

167. Levine S. The Ontogeny of the Hypothalamic-Pituitary-Adrenal Axis. The Influence of Maternal Factors. Annals of the New York Academy of Sciences. 1994; 746(1):275-288. [PubMed: 7825883]

168. Schanberg SM, Field TM. Sensory deprivation stress and supplemental stimulation in the rat pup and preterm human neonate. Child Development. 1987; 58(6):1431-1447. [PubMed: 3691193]

169. Suderman, M., et al. Conserved epigenetic sensitivity to early life experience in the rat and human hippocampus; Proceedings of the National Academy of Sciences; 2012.

170. Labonté B, et al. Genome-wide epigenetic regulation by early-life trauma. Archives of General Psychiatry. 2012; 69(7):722-731. [PubMed: 22752237]

171. Hallmayer J, et al. GEnetic heritability and shared environmental factors among twin pairs with autism. Archives of General Psychiatry. 2011; 68(11):1095-1102. [PubMed: 21727249]

172. Roberts AL, et al. Association of maternal exposure to childhood abuse with elevated risk for autism in offspring. JAMA Psychiatry. 2013; 70(5):508-515. [PubMed: 23553149]

173. Lauritsen MB, Pedersen CB, Mortensen PB. Effects of familial risk factors and place of birth on the risk of autism: a nationwide register-based study. Journal of Child Psychology and Psychiatry. 2005; 46(9):963-971. [PubMed: 16108999] 
174. Daniels JL, et al. Parental psychiatric disorders associated with autism spectrum disorders in the offspring. Pediatrics. 2008; 121(5):e1357-e1362. [PubMed: 18450879]

175. Larsson HJ, et al. Risk factors for autism: perinatal factors, parental psychiatric history, and socioeconomic status. American Journal of Epidemiology. 2005; 161(10):916-925. [PubMed: 15870155]

176. Jokiranta E, et al. Parental psychiatric disorders and autism spectrum disorders. Psychiatry Research. 2013; 207(3):203-211. [PubMed: 23391634]

177. Piven J, Palmer P. Psychiatric disorder and the broad autism phenotype: evidence from a family study of multiple-incidence autism families. Am J Psychiatry. 1999; 156(4):557-63. [PubMed: 10200734]

178. Eisinger B, et al. Development of a versatile enrichment analysis tool reveals associations between the maternal brain and mental health disorders, including autism. BMC Neuroscience. 2013; 14(1):147. [PubMed: 24245670]

179. Driessen T, et al. Genes showing altered expression in the medial preoptic area in the highly social maternal phenotype are related to autism and other disorders with social deficits. BMC Neuroscience. 2014; 15(1):11. [PubMed: 24423034]

180. Insel TR. The Challenge of Translation in Social Neuroscience: A Review of Oxytocin, Vasopressin, and Affiliative Behavior. Neuron. 2010:65.

181. Nephew, BC. Behavioral roles of oxytocin and vasopressin. In: Sumiyoshi, T., editor. Neuroendocrinology and Behavior. 2012. InTech

182. Skrundz M, et al. Plasma Oxytocin Concentration during Pregnancy is associated with Development of Postpartum Depression. Neuropsychopharmacology. 2011; 36(9):1886-1893. [PubMed: 21562482]

183. Bales KL, Perkeybile AM. Developmental experiences and the oxytocin receptor system. Hormones and Behavior. 2012; 61(3):313-319. [PubMed: 22245313]

184. Carter CS, et al. Consequences of early experiences and exposure to oxytocin and vasopressin are sexuallly dimorphic. Developmental Neurosci. 2009; 31(4):25-37.

185. Veenema AH. Toward understanding how early-life social experiences alter oxytocin- and vasopressin-regulated social behaviors. Hormones and Behavior. 2012; 61(3):304-12. [PubMed: 22197269]

186. Nephew B, Murgatroyd C. The role of maternal care in shaping CNS function. Neuropeptides. 2013; 47(6):371-378. [PubMed: 24210943]

187. Taylor SE, Saphire-Bernstein S, Seeman TE. Are Plasma Oxytocin in Women and Plasma Vasopressin in Men Biomarkers of Distressed Pair-Bond Relationships? Psychological Science. 2010; 21(1):3-7. [PubMed: 20424014]

188. Weisman O, et al. Plasma oxytocin distributions in a large cohort of women and men and their gender-specific associations with anxiety. Psychoneuroendocrinology. 2013; 38(5):694-701. [PubMed: 22999263]

189. Cyranowski JM, et al. Evidence of Dysregulated Peripheral Oxytocin Release Among Depressed Women. Psychosomatic Medicine. 2008; 70(9):967-975. [PubMed: 19005082]

190. Miller M, et al. Oxytocin and Vasopressin in Children and Adolescents With Autism Spectrum Disorders: Sex Differences and Associations With Symptoms. Autism Research. 2013; 6(2):91102. [PubMed: 23413037]

191. Jacob S, et al. Association of the oxytocin receptor gene (OXTR) in Caucasian children and adolescents with autism. Neuroscience Letters. 2007; 417(1):6-9. [PubMed: 17383819]

192. Gregory S, et al. Genomic and epigenetic evidence for oxytocin receptor deficiency in autism. BMC Medicine. 2009; 7(1):62. [PubMed: 19845972]

193. Green JJ, Hollander E. Autism and Oxytocin: New Developments in Translational Approaches to Therapeutics. Neurotherapeutics. 2010; 7(3):250-257. [PubMed: 20643377]

194. Glasson EJ, et al. Perinatal factors and the development of autism: A population study. Archives of General Psychiatry. 2004; 61(6):618-627. [PubMed: 15184241]

195. Gardener H, Spiegelman D, Buka SL. Perinatal and neonatal risk factors for autism: A comprehensive meta-analysis. Pediatrics. 2011; 128(2):344-355. [PubMed: 21746727] 
196. Gregory SG, et al. Association of autism with induced or augmented childbirth in north carolina birth record (1990-1998) and education research (1997-2007) databases. JAMA Pediatrics. 2013; 167(10):959-966. [PubMed: 23938610]

197. Hashemi F, et al. Effect of a Single Neonatal Oxytocin Treatment (Hormonal Imprinting) on the Biogenic Amine Level of the Adult Rat Brain: Could Oxytocin-Induced Labor Cause Pervasive Developmental Diseases? Reproductive Sciences. 2013

198. Al-Farsi YM, et al. Effect of suboptimal breast-feeding on occurrence of autism: A case-control study. Nutrition. 2012; 28(7-8):e27-e32. [PubMed: 22541054]

199. Tanoue Y, Oda S. Weaning time of children with infantile autism. Journal of Autism and Developmental Disorders. 1989; 19(3):425-434. [PubMed: 2793787]

200. Schultz ST, et al. Breastfeeding, infant formula supplementation, and Autistic Disorder: the results of a parent survey. Int Breastfeed J. 2006; 1:16. [PubMed: 16978397]

201. Steinman G, Mankuta D. Breastfeeding as a possible deterrent to autism - A clinical perspective. Medical Hypotheses. 2013; 81(6):999-1001. [PubMed: 24099931]

202. Dennis CL, McQueen K. The Relationship Between Infant-Feeding Outcomes and Postpartum Depression: A Qualitative Systematic Review. Pediatrics. 2009; 123(4):e736-e751. [PubMed: 19336362]

203. Dennis CL, McQueen K. Does maternal postpartum depressive symptomatology influence infant feeding outcomes? Acta Pædiatrica. 2007; 96(4):590-594.

204. Adewuya AO, et al. Impact of postnatal depression on infants' growth in Nigeria. Journal of affective disorders. 2008; 108(1-2):191-193. [PubMed: 17997163]

205. Ahluwalia IB, Morrow B, Hsia J. Why Do Women Stop Breastfeeding? Findings From the Pregnancy Risk Assessment and Monitoring System. Pediatrics. 2005; 116(6):1408-1412. [PubMed: 16322165]

206. Stuebe AM, et al. Failed lactation and perinatal depression: common problems with shared neuroendocrine mechanisms? Journal of Women's Health. 2012; 21(3):264-72.

207. Dawson G, Bernier R. A quarter century of progress on the early detection and treatment of autism spectrum disorder. Development and Psychopathology. 2013; 25(25th Anniversary Special Issue 4pt2):1455-1472. [PubMed: 24342850]

208. Dawson G, et al. Randomized, Controlled Trial of an Intervention for Toddlers With Autism: The Early Start Denver Model. Pediatrics. 2010; 125(1):e17-e23. [PubMed: 19948568]

209. Warren Z, et al. A Systematic Review of Early Intensive Intervention for Autism Spectrum Disorders. Pediatrics. 2011; 127(5):e1303-e1311. [PubMed: 21464190]

210. Landa RJ, et al. Intervention targeting development of socially synchronous engagement in toddlers with autism spectrum disorder: a randomized controlled trial. Journal of Child Psychology and Psychiatry. 2011; 52(1):13-21. [PubMed: 21126245]

211. Bearss K, et al. A Pilot Study of Parent Training in Young Children with Autism Spectrum Disorders and Disruptive Behavior. Journal of Autism and Developmental Disorders. 2013; 43(4):829-840. [PubMed: 22941342]

212. Rogers SJ, et al. Effects of a Brief Early Start Denver Model (ESDM)-Based Parent Intervention on Toddlers at Risk for Autism Spectrum Disorders: A Randomized Controlled Trial. Journal of the American Academy of Child \& Adolescent Psychiatry. 2012; 51(10):1052-1065. [PubMed: 23021480]

213. Mazurek MO, Kanne SM, Miles JH. Predicting improvement in social-communication symptoms of autism spectrum disorders using retrospective treatment data. Research in Autism Spectrum Disorders. 2012; 6(1):535-545.

214. Zwaigenbaum L, Bryson S, Garon N. Early identification of autism spectrum disorders. Behavioural Brain Research. 2013; 251(0):133-146. [PubMed: 23588272]

215. Cryan JF, Dinan TG. Mind-altering microorganisms: the impact of the gut microbiota on brain and behaviour. Nat Rev Neurosci. 2012; 13(10):701-12. [PubMed: 22968153]

216. Tillisch K, et al. Consumption of fermented milk product with probiotic modulates brain activity. Gastroenterology. 2013; 144(7):1394-401. [PubMed: 23474283] 
217. Bravo JA, et al. Ingestion of Lactobacillus strain regulates emotional behavior and central GABA receptor expression in a mouse via the vagus nerve. Proc Natl Acad Sci U S A. 2011; 108(38): 16050-5. [PubMed: 21876150]

218. Ochoa-Reparaz J, et al. Central nervous system demyelinating disease protection by the human commensal Bacteroides fragilis depends on polysaccharide A expression. J Immunol. 2010; 185(7):4101-8. [PubMed: 20817872]

219. Messaoudi M, et al. Assessment of psychotropic-like properties of a probiotic formulation (Lactobacillus helveticus R0052 and Bifidobacterium longum R0175) in rats and human subjects. Br J Nutr. 2011; 105(5):755-64. [PubMed: 20974015]

220. Rao AV, et al. A randomized, double-blind, placebo-controlled pilot study of a probiotic in emotional symptoms of chronic fatigue syndrome. Gut Pathog. 2009; 1(1):1757-4749.

221. O’Mahony SM, et al. Early Life Stress Alters Behavior, Immunity, and Microbiota in Rats: Implications for Irritable Bowel Syndrome and Psychiatric Illnesses. Biological Psychiatry. 2009; 65(3):263-267. [PubMed: 18723164]

222. O'Mahony SM, et al. Maternal separation as a model of brain-gut axis dysfunction. Psychopharmacology. 2011; 214(1):71-88. [PubMed: 20886335]

223. Hsiao Elaine Y, et al. Microbiota Modulate Behavioral and Physiological Abnormalities Associated with Neurodevelopmental Disorders. Cell. 2013; 155(7):1451-1463. [PubMed: 24315484]

224. Pequegnat B, et al. A vaccine and diagnostic target for Clostridium bolteae, an autism-associated bacterium. Vaccine. 2013; 31(26):2787-2790. [PubMed: 23602537]

225. Dominguez-Bello MG, et al. Delivery mode shapes the acquisition and structure of the initial microbiota across multiple body habitats in newborns. Proceedings of the National Academy of Sciences. 2010; 107(26):11971-11975.

226. Penders J, et al. Factors influencing the composition of the intestinal microbiota in early infancy. Pediatrics. 2006; 118(2):511-521. [PubMed: 16882802]

227. Azad MB, et al. Gut microbiota of healthy Canadian infants: profiles by mode of delivery and infant diet at 4 months. Canadian Medical Association Journal. 2013

228. Deykin EY, MacMahon B. Pregnancy, delivery, and neonatal complications among autistic children. Am J Dis Child. 1980; 134(9):860-4. [PubMed: 7416112]

229. Davidson JR, et al. Post-traumatic stress disorder in the community: an epidemiological study. Psychol Med. 1991; 21(3):713-21. [PubMed: 1946860]

230. van Zuiden M, et al. Predicting PTSD: Pre-existing vulnerabilities in glucocorticoid-signaling and implications for preventive interventions. Brain, Behavior, and Immunity. 2013; 30(0):12-21.

231. Javidi H, Yadollahie M. Post-traumatic Stress Disorder. Int J Occup Environ Med. 2012; 3(1):29. [PubMed: 23022845]

232. Cerda M, et al. Psychopathology in the aftermath of the Haiti earthquake: a population-based study of posttraumatic stress disorder and major depression. Depress Anxiety. 2013; 30(5):41324. [PubMed: 23124841]

233. Skogstad M, et al. Work-related post-traumatic stress disorder. Occup Med. 2013; 63(3):175-82.

234. Pietrzak RH, et al. Trajectories of PTSD risk and resilience in World Trade Center responders: an 8-year prospective cohort study. Psychol Med. 2014; 44(1):205-19. [PubMed: 23551932]

235. Beck CT, et al. Posttraumatic stress disorder in new mothers: results from a two-stage U.S. national survey. Birth. 2011; 38(3):216-27. [PubMed: 21884230]

236. McCutcheon VV, et al. Age at trauma exposure and PTSD risk in young adult women. J Trauma Stress. 2010; 23(6):811-4. [PubMed: 20963847]

237. Feldman R, Vengrober A. Posttraumatic stress disorder in infants and young children exposed to war-related trauma. J Am Acad Child Adolesc Psychiatry. 2011; 50(7):645-58. [PubMed: 21703492]

238. Otto MW, et al. Posttraumatic stress disorder symptoms following media exposure to tragic events: impact of 9/11 on children at risk for anxiety disorders. J Anxiety Disord. 2007; 21(7): 888-902. [PubMed: 17276653] 
239. Yehuda R, et al. Maternal, not paternal, PTSD is related to increased risk for PTSD in offspring of Holocaust survivors. Journal of Psychiatric Research. 2008; 42(13):1104-1111. [PubMed: 18281061]

240. Roberts AL, et al. Posttraumatic Stress Disorder Across Two Generations: Concordance and Mechanisms in a Population-Based Sample. Biological Psychiatry. 2012; 72(6):505-511. [PubMed: 22521146]

241. Hairston IS, et al. The role of infant sleep in intergenerational transmission of trauma. Sleep. 2011; 34(10):1373-83. [PubMed: 21966069]

242. Muzik M, Marcus SM, Flynn HA. Psychotherapeutic treatment options for perinatal depression: emphasis on maternal-infant dyadic outcomes. The Journal of clinical psychiatry. 2009; 70(9): 1318-9. [PubMed: 19818252]

243. Muzik M, et al. Mother-infant bonding impairment across the first 6 months postpartum: the primacy of psychopathology in women with childhood abuse and neglect histories. Archives of Women's Mental Health. 2013; 16(1):29-38.

244. Schechter DS, et al. An fMRI study of the brain responses of traumatized mothers to viewing their toddlers during separation and play. Soc Cogn Affect Neurosci. 2012; 7(8):969-79. [PubMed: 22021653]

245. Polachek IS, et al. Postpartum post-traumatic stress disorder symptoms: the uninvited birth companion. The Israel Medical Association journal: IMAJ. 2012; 14(6):347-53. [PubMed: 22891394]

246. Beck CT. Post-traumatic stress disorder due to childbirth: The aftermath. Nursing Research. 2004; 53(4):216-224. [PubMed: 15266160]

247. Sorenson DS, Tschetter L. Prevalence of negative birth perception, disaffirmation, perinatal trauma symptoms, and depression among postpartum women. Perspect Psychiatr Care. 2010; 46(1):14-25. [PubMed: 20051075]

248. Giannandrea SA, et al. Increased risk for postpartum psychiatric disorders among women with past pregnancy loss. J Womens Health. 2013; 22(9):760-8.

249. Fan AP, et al. Association between maternal behavior in infancy and adult mental health: A 30year prospective study. Compr Psychiatry. 2014; 55(2):283-9. [PubMed: 24290078]

250. de Kloet CS, et al. Assessment of HPA-axis function in posttraumatic stress disorder: pharmacological and non-pharmacological challenge tests, a review. J Psychiatr Res. 2006; 40(6):550-67. [PubMed: 16214171]

251. Jones T, Moller MD. Implications of hypothalamic-pituitary-adrenal axis functioning in posttraumatic stress disorder. J Am Psychiatr Nurses Assoc. 2011; 17(6):393-403. [PubMed: 22142976]

252. Vanitallie TB. Stress: a risk factor for serious illness. Metabolism. 2002; 51(6 Suppl 1):40-5. [PubMed: 12040540]

253. Yehuda R. Biology of posttraumatic stress disorder. J Clin Psychiatry. 2001; 17:41-6. [PubMed: 11495096]

254. Yehuda R, et al. Putative biological mechanisms for the association between early life adversity and the subsequent development of PTSD. Psychopharmacology. 2010; 212(3):405-417. [PubMed: 20706708]

255. Yehuda R, Halligan SL, Grossman R. Childhood trauma and risk for PTSD: relationship to intergenerational effects of trauma, parental PTSD, and cortisol excretion. Dev Psychopathol. 2001; 13(3):733-53. [PubMed: 11523857]

256. Harris B, et al. Cardiff puerperal mood and hormone study. III. Postnatal depression at 5 to 6 weeks postpartum, and its hormonal correlates across the peripartum period. The British journal of psychiatry: the journal of mental science. 1996; 168(6):739-44. [PubMed: 8773817]

257. O'Donnell KJ, et al. Prenatal maternal mood is associated with altered diurnal cortisol in adolescence. Psychoneuroendocrinology. 2013; 38(9):1630-8. [PubMed: 23433748]

258. Meinlschmidt G, et al. Maternal cortisol in late pregnancy and hypothalamic-pituitary-adrenal reactivity to psychosocial stress postpartum in women. Stress. 2010; 13(2):163-71. [PubMed: 20214437] 
259. Essex MJ, et al. Influence of early life stress on later hypothalamic-pituitary-adrenal axis functioning and its covariation with mental health symptoms: A study of the allostatic process from childhood into adolescence. Development and Psychopathology. 2011; 23(Special Issue 04):1039-1058. [PubMed: 22018080]

260. Marceau K, et al. Disentangling the effects of genetic, prenatal and parenting influences on children's cortisol variability. Stress. 2013; 16(6):607-15. [PubMed: 23947477]

261. Caldji C, Diorio J, Meaney MJ. Variations in maternal care in infancy regulate the development of stress reactivity. Biol Psychiatry. 2000; 48(12):1164-74. [PubMed: 11137058]

262. Diehl LA, et al. Long lasting sex-specific effects upon behavior and S100b levels after maternal separation and exposure to a model of post-traumatic stress disorder in rats. Brain research. 2007; 1144(0):107-116. [PubMed: 17335785]

263. Lutz PE, Turecki G. DNA methylation and childhood maltreatment: From animal models to human studies. Neuroscience. 2013; 8(13):00670-2.

264. Imanaka A, et al. Importance of early environment in the development of post-traumatic stress disorder-like behaviors. Behavioural Brain Research. 2006; 173(1):129-137. [PubMed: 16860405]

265. Essex MJ, et al. Maternal stress beginning in infancy may sensitize children to later stress exposure: effects on cortisol and behavior. Biological Psychiatry. 2002; 52(8):776-784. [PubMed: 12372649]

266. Tyrka AR, et al. Childhood parental loss and adult hypothalamic-pituitary-adrenal function. Biol Psychiatry. 2008; 63:1147-1154. [PubMed: 18339361]

267. Dougherty LR, et al. Early exposure to parental depression and parenting: associations with young offspring's stress physiology and oppositional behavior. Journal of Abnormal Child Psychology. 2013; 41(8):1299-310. [PubMed: 23722864]

268. Laurent HK, et al. Effects of prenatal and postnatal parent depressive symptoms on adopted child HPA regulation: Independent and moderated influences. Developmental Psychology. 2013; 49(5):876-886. [PubMed: 22686176]

269. Weems CF V, Carrion G. The association between PTSD symptoms and salivary cortisol in youth: the role of time since the trauma. J Trauma Stress. 2007; 20(5):903-7. [PubMed: 17955527]

270. Essex MJ, et al. Epigenetic Vestiges of Early Developmental Adversity: Childhood Stress Exposure and DNA Methylation in Adolescence. Child Development. 2013; 84(1):58-75. [PubMed: 21883162]

271. McGowan PO. Epigenomic mechanisms of early adversity and HPA dysfunction: Considerations for PTSD research. Frontiers in Psychiatry. 2013:4. [PubMed: 23444313]

272. Raabe FJ, Spengler D. Epigenetic Risk Factors in PTSD and Depression. Frontiers in Psychiatry. 2013:4. [PubMed: 23444313] 


\section{Research Highlights}

- Cross-domain postpartum depression and anxiety studies may identify novel preventative measures for psychiatric disorders.

- The study of several psychiatric disorders will benefit from ethologically relevant cross domain animal studies.

- Longitudinal cross domain clinical studies are also needed to identify novel preventative measures.

- Increased communication between clinicians and animal researchers in the development of cross domain studies is needed. 